\title{
Phospholipase C-Mediated Suppression of Dark Noise Enables Single-Photon Detection in Drosophila Photoreceptors
}

\author{
Ben Katz and Baruch Minke \\ Departments of Medical Neurobiology, the Institute of Medical Research Israel-Canada, the Edmond and Lily Safra Center for Brain Sciences, and the \\ Kühne Minerva Center for Studies of Visual Transduction, Faculty of Medicine of the Hebrew University, Jerusalem 91120, Israel
}

Drosophila photoreceptor cells use the ubiquitous G-protein-mediated phospholipase C (PLC) cascade to achieve ultimate singlephoton sensitivity. This is manifested in the single-photon responses (quantum bumps). In photoreceptor cells, dark activation of $\mathrm{G}_{\mathrm{q}} \alpha$ molecules occurs spontaneously and produces unitary dark events (dark bumps). A high rate of spontaneous $\mathrm{G}_{\mathrm{q}} \alpha$ activation and dark bump production potentially hampers single-photon detection. We found that in wild-type flies the in vivo rate of spontaneous $\mathrm{G}_{\mathrm{q}} \alpha$ activation is very high. Nevertheless, this high rate is not manifested in a substantially high rate of dark bumps. Therefore, it is unclear how phototransduction suppresses dark bump production arising from spontaneous $\mathrm{G}_{\mathrm{q}} \alpha$ activation, while still maintaining high-fidelity representation of single photons. In this study we show that reduced PLC catalytic activity selectively suppressed production of dark bumps but not light-induced bumps. Manipulations of PLC activity using PLC mutant flies and $\mathrm{Ca}^{2+}$ modulations revealed that a critical level of PLC activity is required to induce bump production. The required minimal level of PLC activity selectively suppressed random production of single $\mathrm{G}_{\mathrm{q}} \alpha$-activated dark bumps despite a high rate of spontaneous $\mathrm{G}_{\mathrm{q}} \alpha$ activation. This minimal PLC activity level is reliably obtained by photon-induced synchronized activation of several neighboring $\mathrm{G}_{\mathrm{q}} \alpha$ molecules activating several PLC molecules, but not by random activation of single $\mathrm{G}_{\mathrm{q}} \alpha$ molecules. We thus demonstrate how a G-protein-mediated transduction system, with PLC as its target, selectively suppresses its intrinsic noise while preserving reliable signaling.

\section{Introduction}

Fly photoreceptors use G-protein-mediated phospholipase C (PLC) signaling to achieve ultimate sensitivity to single photons, as manifested in single-photon responses (quantum bumps; Yeandle and Spiegler, 1973; Wu and Pak, 1975). Reliable singlephoton detection requires accurate differentiation between quantum bumps and dark noise, which in Drosophila, mainly arises from unitary events that are similar in shape to quantum bumps but smaller in amplitude (dark bumps; Hardie et al., 2002; Elia et al., 2005). The dark bumps are thought to originate from spontaneous $\mathrm{G}_{\mathrm{q}} \alpha$ activation, as evidenced by absence of dark bumps in the $G_{q} \alpha^{1}$ mutant (Hardie et al., 2002) and by the re-

Received Oct. 17, 2011; revised Dec. 22, 2011; accepted Dec. 30, 2011.

Author contributions: B.K. and B.M. designed research; B.K. performed research; B.K. analyzed data; B.K. and B.M. wrote the paper.

This research was supported by grants from the National Eye Institute (R01 EY 03529), the US-Israel Binational Science Foundation, the Israel Science Foundation, and the German Israeli Foundation. We thank Drs. François Payre and Armin Huber for the antibodies against Dmoesin and PLC, respectively; Dr. William L. Pak for the PLC mutants; and Drs. Roger Hardie, Alain Pumir, Johannes Oberwinkler, and Boaz Cook for valuable discussions, for useful comments, and for critical reading of the manuscript. We also thank Drs. Moshe Parnas, Shahar Frechter, Shaya Lev, Maximillian Peters, and David Zeevi for critical reading of the manuscript.

Correspondence should be addressed to Baruch Minke, Department of Medical Neurobiology, Faculty of Medicine, The Hebrew University, P.0. Box 12272, Jerusalem 91120, Israel. E-mail: baruchm@ekmd.huji.ac.il.

DOI:10.1523/JNEUROSCI.5221-11.2012

Copyright $\odot 2012$ the authors $\quad 0270-6474 / 12 / 322722-12 \$ 15.00 / 0$ duced spontaneous $\mathrm{G}$-protein activation when $\mathrm{G}_{\mathrm{q}} \beta$ is found in excess over $\mathrm{G}_{\mathrm{q}} \alpha$ (Elia et al., 2005).

PLC is a key enzyme in fly phototransduction with transient receptor potential (TRP) channels as its targets (Devary et al., 1987; Bloomquist et al., 1988; Selinger and Minke, 1988). In Drosophila photoreceptors the norpA (no receptor potential $A$ ) gene encodes a $\beta$-class PLC, predominately expressed in the signaling compartment (the rhabdomere). Mutations in the norpA gene causing reduced levels of the protein show reduced receptor potential amplitude and slow response termination (Bloomquist et al., 1988). Thus, although PLC $\beta$ is a functional phospholipase, the latter phenotype has led to the discovery that PLC functions as a GTPase-activating protein (GAP) as well. This apparent inability to hydrolyze GTP bound to $\mathrm{G}_{\mathrm{q}} \alpha$ without PLC ensures that every activated G-protein eventually encounters a PLC molecule required for TRP channel activation (Cook et al., 2000). However, the mechanism underlying TRP and TRPL channel gating, downstream of PLC activation, remains unresolved (but see Chyb et al., 1999; Leung et al., 2008; Delgado and Bacigalupo, 2009; Katz and Minke, 2009; Parnas et al., 2009; Huang et al., 2010).

$\mathrm{Ca}^{2+}$ plays a major role in excitation, positive and negative feedback regulation (Hardie, 1991), and adaptation (Gu et al., 2005) of the Drosophila response to light. These processes are attributed to the regulatory effects of $\mathrm{Ca}^{2+}$ on many phototransduction proteins including PLC (Toyoshima et al., 1990; Run- 
Table 1. Extracellular solution

\begin{tabular}{|c|c|c|c|c|c|c|c|c|c|c|}
\hline Solution name & $\mathrm{NaCl}(\mathrm{mm})$ & $\mathrm{KCl}(\mathrm{mm})$ & $\mathrm{MgSO}_{4}(\mathrm{~mm})$ & TES (mm) & $\mathrm{MgCl}_{2}(\mathrm{~mm})$ & $\mathrm{CaCl}_{2}(\mathrm{~mm})$ & $\mathrm{SrCl}_{2}(\mathrm{~mm})$ & $\mathrm{BaCl}_{2}(\mathrm{~mm})$ & L-Proline (mm) & L-Alanine (mm) \\
\hline Low $\mathrm{Ca}^{2+}$ & 125 & 5 & - & 10 & - & - & - & - & 25 & 5 \\
\hline $1.5 \mathrm{~mm} \mathrm{Mg}^{2+}$ & 125 & 5 & - & 10 & 1.5 & - & - & - & 25 & 5 \\
\hline $1.5 \mathrm{mmCa}^{2+}$ & 125 & 5 & - & 10 & - & 1.5 & - & - & 25 & 5 \\
\hline $1.5 \mathrm{~mm} \mathrm{Sr}^{2+}$ & 125 & 5 & - & 10 & - & - & 1.5 & - & 25 & 5 \\
\hline $1.5 \mathrm{~mm} \mathrm{Ba}^{2+}$ & 125 & 5 & - & 10 & - & - & - & 1.5 & 25 & 5 \\
\hline $1.5 \mathrm{~mm} \mathrm{Ca}^{2+}+4 \mathrm{~mm} \mathrm{Mg}^{2+}$ & 120 & 5 & 4 & 10 & - & 1.5 & - & - & 25 & 5 \\
\hline
\end{tabular}

ning Deer et al., 1995; Hardie, 2005). $\mathrm{Ca}^{2+}$ has profound effects on response kinetics (Hardie and Raghu, 2001; Katz and Minke, 2009), but the target proteins and mechanisms are not entirely clear. Recent studies have presented quantitative models that explain how bumps emerge from stochastic nonlinear dynamics of phototransduction. These models explain the reliability of bump formation, effects of external $\mathrm{Ca}^{2+}$ concentration $\left(\left[\mathrm{Ca}^{2+}\right]\right)$ on bump kinetics, and the low background noise in the dark (Pumir et al., 2008; Nikolic et al., 2010). However, the detailed molecular mechanisms differ in the two models, especially with regard to the mechanism underlying dark noise suppression.

In the present study we investigated the mechanism that suppresses dark bump production yet still maintains high-fidelity representation of single photons. This suppression, which occurs despite a relatively high rate of spontaneous $\mathrm{G}_{\mathrm{q}} \alpha$ activation, results from the requirement of a minimal level of PLC activity that is necessary to trigger bump production. The required level of PLC activity is rarely obtained by random activation of single $\mathrm{G}_{\mathrm{q}} \alpha$ molecules but always obtained by photon-induced synchronized activation of several neighboring $\mathrm{G}_{\mathrm{q}} \alpha$ molecules that activate several PLC molecules.

\section{Materials and Methods}

Fly stocks. Flies (Drosophila melanogaster) of either sex were raised at $24^{\circ} \mathrm{C}$ in a $12 \mathrm{~h}$ light/dark cycle on standard medium. Pupae vials were wrapped with aluminum foil and moved into a dark box $12 \mathrm{~h}$ before eclosion (dark adapted) or placed $10 \mathrm{~cm}$ from white fluorescent light (L 36, $20 \mathrm{~W}$; OSRAM) 4-6 h before eclosion (light adapted).

Western blot analysis. For detection of NORPA and $\mathrm{G}_{\mathrm{q}} \alpha$ proteins, 5 newly eclosed dark raised fly heads were used for each lane of Western blots. Proteins were extracted with $1 \times$ SDS-PAGE buffer ( $2 \%$ SDS, 100 mм DTT, $10 \%$ glycerol in $65 \mathrm{~mm}$ Tris- $\mathrm{HCl}, \mathrm{pH} 6.8$ ) and subjected to $6 \%$ or $10 \%$ SDS-polyacrylamide gels for norpA or $\mathrm{G}_{\mathrm{q}} \alpha$, respectively (Midget System, GE Healthcare). Protein levels were detected using anti- $\mathrm{G}_{\mathrm{q}}(1$ : 2000), anti-PLC (1:500) and anti-Dmoesin antibodies (1:10,000). Relative protein amounts on the same gel were determined by quantification of the ECL signal on an exposed film. Bands on the exposed film were quantified using TINA2.0 software. To reduce the variance caused by the experimental procedure, the density in each lane was corrected by the $\alpha$ Moesin signal in the same lane and calculated as a percentage of WT fly signals.

Light stimulation. A xenon high-pressure lamp (PTI, LPS 220, operating at $75 \mathrm{~W}$ ) was used and the light stimuli were delivered to the ommatidia by means of epi-illumination via the objective lens (in situ). The intensity of the orange light (Schott OG 590 edge filter) at the specimen was calibrated by measuring bump rate from WT flies at low $\mathrm{Ca}^{2+}$ conditions (effective photons per second).

Solutions. Components of extracellular and intracellular solutions are listed in Tables 1 and 2, respectively. All solutions were titrated to $\mathrm{pH}$ 7.15 .

Electrophysiology. Dissociated Drosophila ommatidia were prepared as previously described (Peretz et al., 1994) from newly eclosed flies ( $<1 \mathrm{~h}$ after eclosion) and transferred to a recording chamber on an inverted Olympus microscope. Whole-cell recording were performed at $21^{\circ} \mathrm{C}$ using borosilicate patch pipettes of 8-12 $\mathrm{M} \Omega$, an Axopatch 1D (Molecular
Table 2. Intracellular solution

\begin{tabular}{|c|c|c|c|c|c|c|c|c|}
\hline Solution name & $\begin{array}{l}\text { D-Gluconicacid } \\
\text { potassium salt } \\
\text { (KGlu, mm) }\end{array}$ & $\begin{array}{l}\mathrm{MgSO}_{4} \\
(\mathrm{~mm})\end{array}$ & $\begin{array}{l}\text { TES } \\
(\mathrm{mm})\end{array}$ & $\begin{array}{l}\text { MgATP } \\
\text { (mM) }\end{array}$ & $\begin{array}{l}\text { NaGTP } \\
\text { (mm) }\end{array}$ & $\begin{array}{l}\text { GDPTris } \\
\text { (mm) }\end{array}$ & $\begin{array}{l}\text { NAD } \\
(\mathrm{mm})\end{array}$ & $\begin{array}{l}\mathrm{CaCl}_{2} \\
(\mathrm{~mm})\end{array}$ \\
\hline $\begin{array}{l}\text { KGlu (no GDP or } \\
\qquad 0^{\prime} \text { mм }\left[\mathrm{Ca}^{2+}\right]_{\mathrm{i}} \text { ) }\end{array}$ & 140 & 2 & 10 & 4 & 0.4 & - & 1 & - \\
\hline $\begin{array}{l}\mathrm{KGlu}+0.1 \mathrm{~mm} \\
\qquad \mathrm{Ca}^{2+}\left(0.1 \mathrm{~mm}\left[\mathrm{Ca}^{2+}\right]_{\mathrm{i}}\right)\end{array}$ & 140 & 2 & 10 & 4 & 0.4 & - & 1 & 0.1 \\
\hline $\begin{array}{l}\mathrm{KGlu}+0.5 \mathrm{~mm} \\
\qquad \mathrm{Ca}^{2+}\left(0.5 \mathrm{~mm}\left[\mathrm{Ca}^{2+}\right]_{\mathrm{i}}\right)\end{array}$ & 140 & 2 & 10 & 4 & 0.4 & - & 1 & 0.5 \\
\hline $\begin{array}{l}\text { KGlu }+1 \mathrm{~mm} \\
\qquad \mathrm{Ca}^{2+}\left(1 \mathrm{~mm}\left[\mathrm{Ca}^{2+}\right]_{\mathrm{i}}\right)\end{array}$ & 140 & 2 & 10 & 4 & 0.4 & - & 1 & 1 \\
\hline KGlu (-ATP) & 140 & 6 & 10 & - & 0.4 & - & 1 & - \\
\hline KGlu (1 mм ATP) & 140 & 5 & 10 & 1 & 0.4 & - & 1 & - \\
\hline KGlu (8 mм GDP) & 132 & 2 & 10 & 4 & 0.4 & 8 & 1 & - \\
\hline
\end{tabular}

Devices) voltage-clamp amplifier, Digidata 1440A and pClamp 10.2.0.14 software (Molecular Devices). Currents were filtered using the 8-pole low-pass Bessel filter of the patch-clamp amplifier at $5 \mathrm{kHz}$. Series resistance values were $<25 \mathrm{M} \Omega$ and were routinely compensated to $>80 \%$ when recording macroscopic responses $>100 \mathrm{pA}$, but not when recording bumps.

Bump detection. Bumps were detected offline using the event detection threshold search function of pClamp 10.2.0.14 software (Molecular Devices). The following parameters were used: trigger, $-3 \mathrm{pA}$; re-arm, -2 $\mathrm{pA}$; pretrigger, $1 \mathrm{~ms}$; post-trigger, $1 \mathrm{~ms}$; and minimum allowed duration, $10 \mathrm{~ms}$.

\section{Results}

Low $\mathrm{Ca}^{2+}$ selectively abolishes dark bumps but not quantum bumps

In Drosophila photoreceptor cells, dark bump production is thought to occur by spontaneous GDP-GTP exchange on the $\mathrm{G}_{\mathrm{q}} \alpha$ molecules. This notion leads to at least two crucial predictions: (1) dark bump rate should depend linearly on the amount of $\mathrm{G}_{\mathrm{q}} \alpha$ in the rhabdomeric membrane; (2) unfavorable conditions for GDP-GTP exchange should decrease the dark bump rate. To examine whether these predictions are realized, we measured the dark bump rate in flies with different expression levels of $\mathrm{G}_{\mathrm{q}} \alpha$ in the rhabdomeric membrane. To this end we used G-protein mutants and light vs dark rearing conditions which result in $\mathrm{G}_{\mathrm{q}} \alpha$ translocation. Accordingly, raising WT $\left(w^{1118}\right)$ and mutant $G_{q} \alpha^{1}$ heterozygote $\left(G_{q} \alpha^{1} /+\right)$ flies either in light or darkness changed $\mathrm{G}_{\mathrm{q}} \alpha$ distribution between the rhabdomeric membrane and the cytoplasm (Kosloff et al., 2003; Frechter et al., 2007). We found that the dark bump rate depended linearly on $\mathrm{G}_{\mathrm{q}} \alpha$ concentration bound to the rhabdomeric membrane, indicating that dark bump rate depends on activation of individual $\mathrm{G}_{\mathrm{q}} \alpha$ in the signaling compartment (Fig. 1A,B). Moreover, we used pipette solution with a high $(8 \mathrm{mM})$ concentration of GDP (Table 2), which elevated cellular GDP concentration, thereby shifting the equilibrium toward $\mathrm{G}_{\mathrm{q}} \alpha$-GDP. This manipulation largely decreased dark bump rate in WT flies (Fig. 1C,D). To further establish the robustness of dark bump suppression by 
elevated cellular GDP, we performed the experiment in $G \beta e^{1}$ heterozygote $\left(G \beta e^{1}\right.$ / $+)$. $G \beta e^{1} /+$ mutant show a high dark bump rate compared with WT flies in 1.5 $\mathrm{mM} \mathrm{Ca}^{2+}$ containing solution $\left(\sim 7 \mathrm{~s}^{-1}\right.$, $\sim 400 \%$ of WT, Fig. $1 C, D$; Elia et al., 2005). Interestingly, elevation of cellular GDP also decreased dark bump rate in $G \beta e^{1} /+$ mutant flies (Fig. $1 C, D$ ). The above results indicated that the appearance of dark bumps arises from spontaneous GDP-GTP exchange, which is consistent with previous hypotheses (Hardie et al., 2002; Elia et al., 2005; Fig. 1).

The dark bumps have, on the average, a quarter smaller amplitude relative to quantum bumps in normal Ringer's solution containing $1.5 \mathrm{mM} \mathrm{Ca}^{2+}$ and $4 \mathrm{~mm}$ $\mathrm{Mg}^{2+}$ (Hardie et al., 2002). This relatively small amplitude of the dark bumps can be increased by removing external $\mathrm{Mg}^{2+}$ (Hardie and Mojet, 1995; Parnas et al., 2007). We therefore removed $\mathrm{Mg}^{2+}$ from the external solution throughout this study to reliably detect the occurrence of dark bumps.

When recording from WT photoreceptors in $\mathrm{Ca}^{2+}$ containing extracellular solution at total darkness, small-amplitude dark bumps are readily observed $(\sim 2$ $\mathrm{s}^{-1}$, Fig. $\left.2 A, B\right)$. This low dark bump rate is not expected to hamper quantum bump detection as they rarely sum up. Strikingly, when $\mathrm{Ca}^{2+}$ was removed from the external solution (low $\mathrm{Ca}^{2+}$ ), dark bump activity was eliminated (Fig. $2 A-C$ ). This phenomenon was not accompanied by the impairment of light excitation, as quantum bumps of high amplitude but of slower waveform were readily elicited under this condition (Fig. $2 \mathrm{~A}$; for measurements of bump kinetics, see Fig. 9). In general, when $\mathrm{Ca}^{2+}$ was omitted from the extracellular solution, dark bumps were virtually absent $\left(<2 \mathrm{~min}^{-1}\right)$ while, in the presence of $\mathrm{Ca}^{2+}$, dark bumps were readily seen (Fig. $2 B, C$ ). To further establish the robustness of dark bump disappearance under low external $\mathrm{Ca}^{2+}$, we explored the $\mathrm{Ca}^{2+}$ dependence of dark bumps in $G \beta e^{1} /+$ mutant flies. Removing extracellular $\mathrm{Ca}^{2+}$ virtually abolished the observed high rate of dark bump activity also in the $G \beta e^{1} /+$ mutant (Fig. $2 B, C$ ).

To further analyze the $\mathrm{Ca}^{2+}$ dependence of dark bump production, we elevated intracellular $\left[\mathrm{Ca}^{2+}\right]$ in the recording pipette in a dose-dependent manner, while keeping low $\mathrm{Ca}^{2+}$ solution in the bath. Elevation of $\left[\mathrm{Ca}^{2+}\right]_{\mathrm{i}}$ up to $1 \mathrm{~mm}$, significantly increased the formation of dark bumps in WT flies (Fig. 3, Table 2). The need for a very high $\mathrm{Ca}^{2+}$ concentration in the recording pipette to induce dark bumps is explained by the existence of a high concentration of intracellular $\mathrm{Ca}^{2+}$ buffers in addition to a powerful $\mathrm{Ca}^{2+}$ extrusion system, which slow down free diffusion of $\mathrm{Ca}^{2+}$ between the cell body and rhabdomere (Oberwinkler and Stavenga, 2000). Figure 3 suggests that a $\mathrm{Ca}^{2+}$ dependent protein/s is specifically required for dark bump production and that $\mathrm{Ca}^{2+}$ is a limiting factor for dark bump production.
B

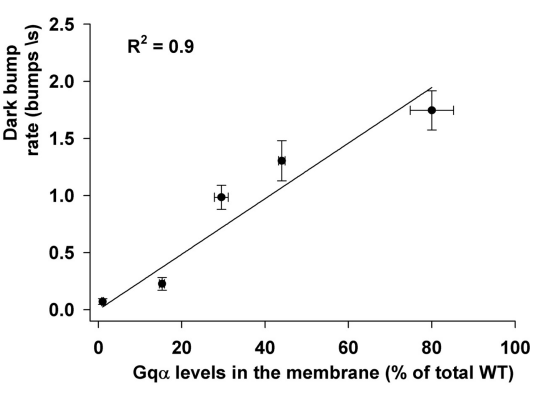

$\mathrm{D}$

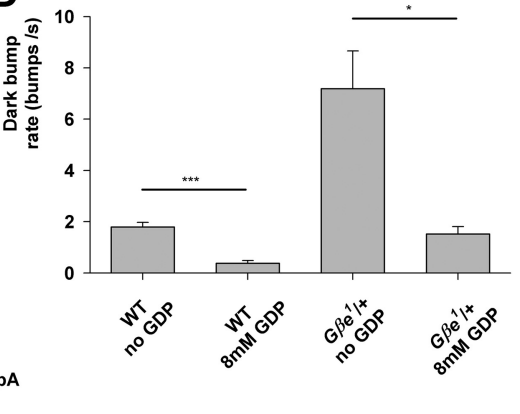

High rate of dark bumps hampers single-photon detection

The appearance of dark bumps is likely to hamper single-photon detection. To quantify the "dark noise" we plotted the root mean square (RMS) of current fluctuations recorded during dark and dim lights (Fig. $2 A, B, D$ ). The figure shows that elimination of the dark bumps under low $\mathrm{Ca}^{2+}$ conditions reduced the RMS [RMS; WT Dark $\left(\right.$ low $\left.\mathrm{Ca}^{2+}\right)=1.15$, WT Dark $\left(1.5 \mathrm{mM} \mathrm{Ca}^{2+}\right)=2.1$ Figs. $2 A, D, 4 F]$. However, dark bumps appear at a low rate of $\sim 2$ $\mathrm{s}^{-1}$ (Fig. 2C; Hardie et al., 2002). This relatively low rate of dark bumps might not impose a difficulty for reliably detecting the light-induced bumps at dim light, due to the smaller amplitude of the dark bumps relative to the quantum bumps (Fig. $2 A$ ). However, at higher dark bump rates of $>8 \mathrm{~s}^{-1}$, bumps occasionally overlap, sum up and produce currents similar in size to the quantum bumps (Fig. $2 B$, arrows). Such high rates of dark bumps are observed in the $G \beta e^{1} /+$ mutant (Fig. $2 B$ ), which hampers singlephoton detection. This is manifested in the RMS similarity of WT illuminated by dim light and the $G \beta e^{1} /+$ mutant in darkness (RMS; WT Light $\left(1.5 \mathrm{~mm} \mathrm{Ca}^{2+}\right)=4.8, G \beta e^{1} /+$ Dark $(1.5 \mathrm{~mm}$ $\left.\mathrm{Ca}^{2+}\right)=3.8$, Figs. $\left.2 D, 4 F\right)$. This observation emphasizes the strong effect that dark bump rate has on dark noise (Fig. $2 B, D$; Elia et al., 2005).

The disappearance of dark bumps under low $\mathrm{Ca}^{2+}$ conditions in WT fly and $G \beta e^{1} /+$ mutant, may be explained by $\mathrm{Ca}^{2+}$ regulation of spontaneous GDP-GTP exchange on $\mathrm{G}_{\mathrm{q}} \alpha$, even though the activation of rhodopsin can facilitate exchange in the absence of $\mathrm{Ca}^{2+}$. To test this possibility we examined whether spontaneous exchange continues under low $\mathrm{Ca}^{2+}$ conditions but is not manifested in bump production. To this end, we explored 
A

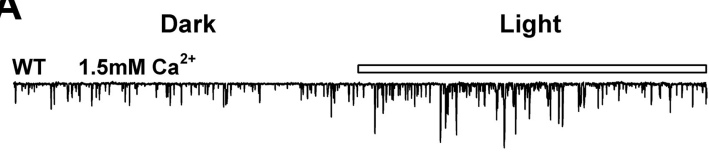

WT Low $\mathrm{Ca}^{2+}$

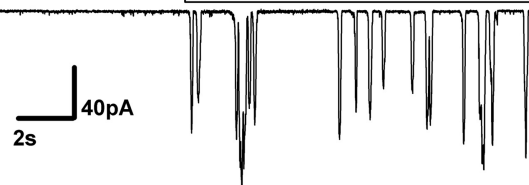

C

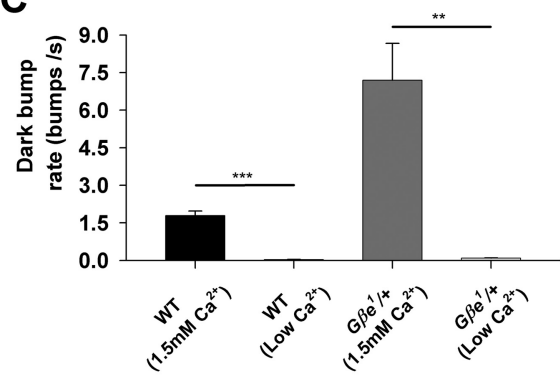

B

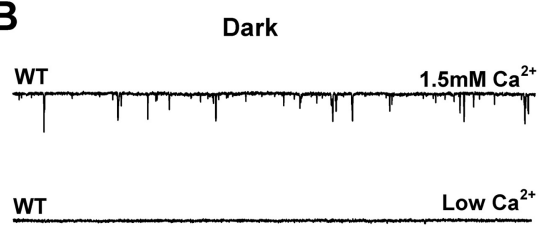

D

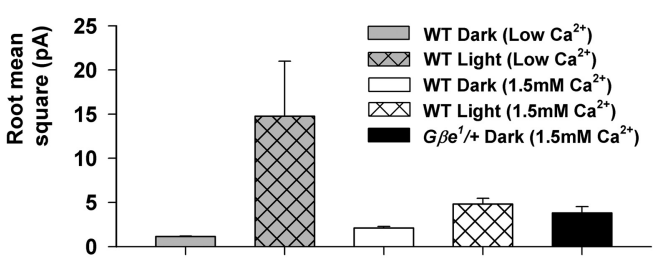

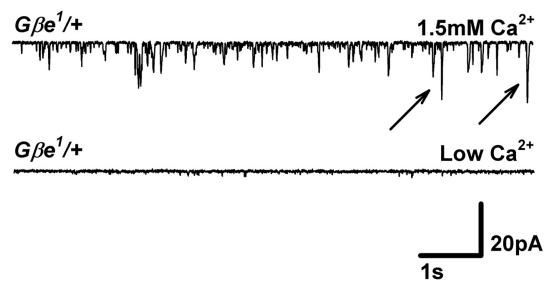

E

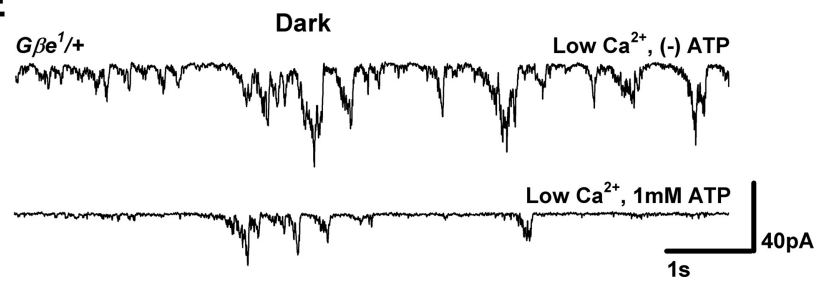

Figure 2. Reduced external $\mathrm{Ca}^{2+}$ eliminates dark bump activity while the amplitudes of light-induced bumps are enhanced. $A$, Whole-cell recordings from WT flies in total darkness and in dim light stimulation of 1 effective photon/s (EP/s) under $1.5 \mathrm{~mm} \mathrm{Ca}^{2+}$ (top trace) and low $\mathrm{Ca}^{2+}$ conditions (bottom trace). Note that no dark bump activity is seen under low Ca ${ }^{2+}$ conditions, while a response to light stimulation is observed. In extracellular solution containing $1.5 \mathrm{~mm} \mathrm{Ca}^{2+}$, dark bumps appear and light response is maintained. $\boldsymbol{B}$, Whole-cell recordings from WT and $G \beta e^{1} /+$ mutant flies at total darkness under $1.5 \mathrm{~mm} \mathrm{Ca}{ }^{2+}$ and low $\mathrm{Ca}^{2+}$ conditions. Note the summation of dark bumps (arrow). Also note the high dark bump rate of $G \beta e^{1} /+$ mutant flies and the highly reduced dark bump activity under low $\mathrm{Ca}^{2+}$ conditions. C, Histogram plotting the mean dark bump rate of the mutant flies at the designated conditions $\left(n=5\right.$, mean \pm SEM, ${ }^{* * *} p<0.01$, ${ }^{* * *} p<$ 0.001). D, RMS of current fluctuation of dark and light $(1 \mathrm{EP} / \mathrm{s})$ responses, at the designated conditions $\left(n=5\right.$, mean \pm SEM). Note, the low RMS under low $\mathrm{Ca}^{2+}$ compared with $1.5 \mathrm{~mm} \mathrm{Ca}^{2+}$ conditions in the dark and the high RMS at low $\mathrm{Ca}^{2+}$ compared with $1.5 \mathrm{~mm} \mathrm{Ca}^{2+}$ conditions in the light. Also, note the similarity between the RMS of $G \beta e^{1} /+$ dark and WT light under $1.5 \mathrm{~mm}$ $\mathrm{Ca}^{2+}$. E, Whole-cell recordings in total darkness from $G \beta e^{1} /+$ mutant flies under low $\mathrm{Ca}^{2+}$ conditions with intracellular solution without ATP (top trace) or with $1 \mathrm{~mm}$ ATP in the pipette (bottom trace) $(n=3)$. Note that dark bumps reappear at these conditions.

whether spontaneous exchange takes place under low $\mathrm{Ca}^{2+}$ conditions, when ATP was removed from the recording pipette (Fig. $2 E$, Table 2). It has been previously shown that reduction of ATP concentration in the recording pipette increases the mean bump amplitude. This is mainly due to inhibition of DAG kinase activity, leading to accumulation of PLC products. This manipulation enhances light excitation of the channels in mutant flies via these products (Hardie et al., 2002). Strikingly, lowering the ATP concentration in the recording pipette caused the reappearance of dark bumps in a dose-dependent manner in the $G \beta e^{1} /+$ mutant, despite the low $\mathrm{Ca}^{2+}$ conditions (Fig. $2 \mathrm{E}$ ). The reappearance of dark bumps under low $\mathrm{Ca}^{2+}$ conditions strongly supports the notion that GDP-GTP exchange at the $\mathrm{G}_{\mathrm{q}} \alpha$ subunit is a $\mathrm{Ca}^{2+}$ independent process and continues under low $\mathrm{Ca}^{2+}$ conditions. This result indicates that low $\mathrm{Ca}^{2+}$ suppresses dark bump production downstream of $\mathrm{G}_{\mathrm{q}} \alpha$.

Figure 2 clearly shows that dark bump production is $\mathrm{Ca}^{2+}$ dependent. However, in light of Figure 2E, it is unclear whether all spontaneous $\mathrm{G}_{\mathrm{q}} \alpha$ activations are manifested in bump production under physiological conditions (i.e., at $\sim 1.5 \mathrm{~mm}$ external $\mathrm{Ca}^{2+}$ ). Accordingly, we examined whether the rate of dark bumps is already attenuated under normal $\mathrm{Ca}^{2+}$ conditions, despite much higher spontaneous $\mathrm{G}_{\mathrm{q}} \alpha$ activation. To this end, we used dark bump rate following removal of ATP from the recording pipette, as a sensitive bioassay for estimating the actual spontaneous $\mathrm{G}_{\mathrm{q}} \alpha$ activation in WT flies. Strikingly, the observed dark bump rate increased with time after whole-cell formation, with ATP removed from the recording pipette and reached a bump rate of $\sim 10 \mathrm{~s}^{-1}$ after $40 \mathrm{~s}$ (Fig. $4 A, C$ ). In contrast, when the recording pipette contained $4 \mathrm{mM} A T P$, no change in bump rate was observed (Fig. $4 B, C$ ). To ensure that the high rate of dark bumps observed in WT flies, under low ATP conditions, was a consequence of spontaneous $\mathrm{G}_{\mathrm{q}} \alpha$ activation, we recorded dark bumps from the $G_{q} \alpha^{1}$ mutant fly under reduced ATP conditions as well. Importantly, only scarce dark bumps were observed in the $G_{q} \alpha^{1}$ mutant, indicating that in WT flies the high bump rate under reduced ATP conditions is $\mathrm{G}_{\mathrm{q}} \alpha$ dependent (Fig. $4 A$, bottom, $B, C$ ).

To further support the notion that the rate of spontaneous $\mathrm{G}_{\mathrm{q}} \alpha$ activation is higher than the observed dark bump rate under normal $\mathrm{Ca}^{2+}$ conditions, we applied an additional strategy. Figure 3 already showed that elevation of cellular $\left[\mathrm{Ca}^{2+}\right]$ induced the appearance of dark bumps under low $\mathrm{Ca}^{2+}$ conditions. We therefore examined whether increasing cellular $\left[\mathrm{Ca}^{2+}\right]$ under 1.5 $\mathrm{mM}$ external $\mathrm{Ca}^{2+}$ concentration conditions would further increase dark bump rate. Indeed, Figure $4, D$ and $E$, shows that bump rate was doubled by increasing cellular $\left[\mathrm{Ca}^{2+}\right]$, thus further supporting the above notion. Moreover, in the $G_{q} \alpha^{1}$ mutant, increasing cellular $\left[\mathrm{Ca}^{2+}\right]$ via the recording pipette did not result in the appearance of dark bumps (Fig. $4 D, E$ ). An additional way to temporarily increase cellular $\left[\mathrm{Ca}^{2+}\right]$ is obtained by replacing a low $\mathrm{Ca}^{2+}$ external solution with a $1.5 \mathrm{mM} \mathrm{Ca}^{2+}$ containing solu- 
A

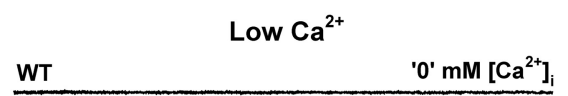

$0.1 \mathrm{mM}\left[\mathrm{Ca}^{2+}\right]_{\mathrm{i}}$
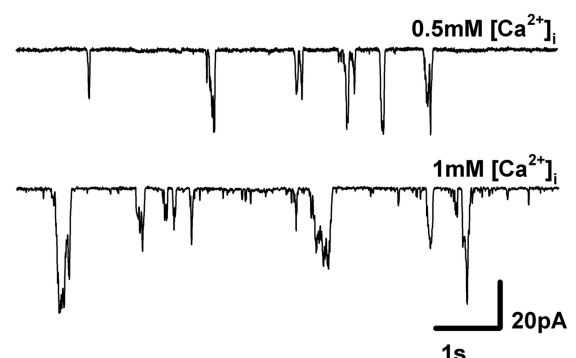

B

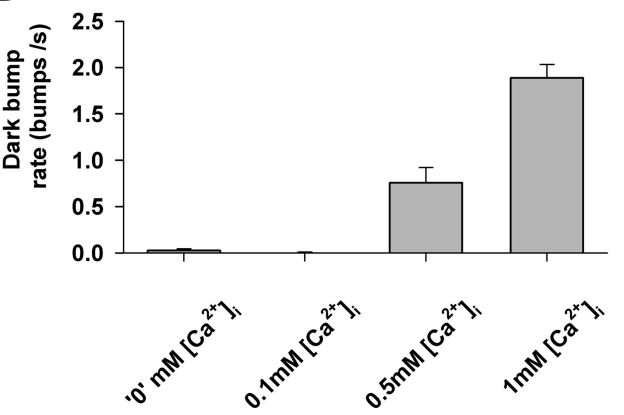

Figure 3. Under low external $\mathrm{Ca}^{2+}$ conditions, elevating $\mathrm{Ca}^{2+}$ concentration in the patchpipette solution results in reappearance of dark bumps in a dose-dependent manner. $\boldsymbol{A}$, Wholecell recordings from WT photoreceptors at total darkness and under low external $\mathrm{Ca}^{2+}$ conditions under various concentrations of $\mathrm{Ca}^{2+}$ in the recording pipette. $\boldsymbol{B}$, Histogram plotting the mean bump rate of dark bumps at the different conditions. Note that the bump rate increased in a dose-dependent manner ( $n=5$, mean \pm SEM).

tion, which temporarily modifies the equilibrium of the $\mathrm{Na}^{+}{ }_{-}$ $\mathrm{Ca}^{2+}$ exchanger. The external $\mathrm{Ca}^{2+}$ manipulations resulted in reverse action of the $\mathrm{Na}^{+}-\mathrm{Ca}^{2+}$ exchanger, transporting $\mathrm{Ca}^{2+}$ into the cell, as evidenced by a small outward $\mathrm{Na}^{+}-\mathrm{Ca}^{2+}$ exchange current (Fig. 4F) (Hardie, 1995). This procedure largely increased dark bump rate and strongly suppressed single-photon detection, as evidenced by the virtual inability to discriminate between quantum bumps and dark bumps (Fig. $4 F$ ).

Importantly, these observations indicate that although the rate of spontaneous $\mathrm{G}_{\mathrm{q}} \alpha$ activation is at least $10 \mathrm{~s}^{-1}$, this high rate is not manifested in a comparably high rate of dark bump production under physiological conditions. Therefore, we set out to decipher the mechanism underlying suppression of dark bump production under physiological conditions, despite the high rate of spontaneous $\mathrm{G}_{\mathrm{q}} \alpha$ activation.

\section{Low $\mathrm{Ca}^{2+}$ suppressed light excitation of the $G_{q} \boldsymbol{\alpha}^{1}$ mutant}

The dark bumps are produced by activation of single $\mathrm{G}_{\mathrm{q}} \alpha$ molecules and are characterized by relatively small amplitude and low $\mathrm{Ca}^{2+}$ suppression (Fig. 2). The light-induced bumps of the $G_{q} \alpha^{1}$ mutant are known to have small amplitudes and are also produced by activation of single $\mathrm{G}_{\mathrm{q}} \alpha$ molecules (Hardie et al., 2002). We therefore sought to examine whether light induced single $\mathrm{G}_{\mathrm{q}} \alpha$ activation is also suppressed by low $\mathrm{Ca}^{2+}$ conditions. To this end we measured the intensity response function ( $R-\log I$ curve) of WT and $G_{q} \alpha^{1}$ mutant flies with and without $\mathrm{Ca}^{2+}$ in the external solution (Fig. 5A). Knowing that the macroscopic response to light is a summation of quantum bumps (Wong et al., 1980;
Barash and Minke, 1994) implies that if bumps of $G_{q} \alpha^{1}$ mutant flies cannot be produced under low $\mathrm{Ca}^{2+}$ conditions, one would expect a highly reduced macroscopic response to light in this mutant under these low $\mathrm{Ca}^{2+}$ conditions. Figure 5 shows that this expectation was realized. Although the $G_{q} \alpha^{1}$ mutant shows highly reduced response amplitude at any light intensity because of its highly reduced $\mathrm{G}_{\mathrm{q}} \alpha$ expression level (Fig. 5C; Scott et al., 1995), it still produces a considerable response to intense lights (Fig. $5 A, B)$. Strikingly, at low external $\left[\mathrm{Ca}^{2+}\right]$, the macroscopic response to light in this mutant was nearly abolished, showing highly reduced amplitude even when the stimulating light intensity was an order of magnitude higher (Fig. $5 A$, inset). Addition of $1 \mathrm{mM} \mathrm{Ca}^{2+}$ into the recording pipette partially rescued the light response under low $\mathrm{Ca}^{2+}$ conditions (Fig. $5 A, B$ ). In contrast, removing external $\mathrm{Ca}^{2+}$ largely enhanced the amplitude of the light-induced current (LIC) of WT flies (Fig. 5B), mainly due to removal of open channel block (Hardie and Mojet, 1995; Parnas et al., 2007). This result demonstrates that light excitation is preserved in WT flies under low $\mathrm{Ca}^{2+}$ conditions. Figures 2 and 5 thus indicate that active single $\mathrm{G}_{\mathrm{q}} \alpha$ molecules, when either activated spontaneously in WT flies or by light in the $G_{q} \alpha^{1}$ mutant are virtually eliminated under low $\mathrm{Ca}^{2+}$ conditions.

\section{Reduction of PLC expression levels or its catalytic activity results in suppression of light excitation under low $\mathrm{Ca}^{2+}$ conditions: a working hypothesis}

The selective abolishment of active single $\mathrm{G}_{\mathrm{q}} \alpha$ molecules under low $\mathrm{Ca}^{2+}$ conditions can be explained by assuming that a critical level of PLC activity is required to produce a bump. Therefore, the $\mathrm{Ca}^{2+}$ dependence of bump production arises from $\mathrm{Ca}^{2+}$ regulation of PLC catalytic activity. When PLC reaches a minimal activity level, it triggers synchronous channel activation downstream of PLC leading to bump production (Pumir et al., 2008). According to this hypothesis, sporadic activation of single $G_{q} \alpha$ molecules in the dark, followed by activation of a single PLC molecule, would fail to induce dark bump formation under low $\mathrm{Ca}^{2+}$ conditions even though dark bumps would be expected to form under normal $\mathrm{Ca}^{2+}$ conditions (Fig. 6A). This failure, under low $\mathrm{Ca}^{2+}$ conditions, results from reduced PLC catalytic activity when the availability of cytosolic $\mathrm{Ca}^{2+}$ is reduced (Toyoshima et al., 1990; Running Deer et al., 1995; Hardie, 2005). On the other hand, photon activation of rhodopsin simultaneously activates several $(\sim 5)$ neighboring $\mathrm{G}_{\mathrm{q}} \alpha$ molecules within $\sim 100 \mathrm{~ms}$, followed by activation of several neighboring PLC molecules (Fig. 6A; Hardie et al., 2002). This photon activation integrates the relatively low activity level of single PLC molecules under low $\mathrm{Ca}^{2+}$ conditions and exceeds the minimal level of integrated PLC activity that is required for synchronous channel activation and resulting in bump production, even under low $\mathrm{Ca}^{2+}$ conditions.

To test this notion we examined 3 cases of reduced integrated PLC activity. A relatively low level of integrated cellular PLC activity can arise from several independent causes: (1) reduction in PLC expression levels due to specific mutations (Pearn et al., 1996); (2) low catalytic activity of PLC due to low $\left[\mathrm{Ca}^{2+}\right]$ (Toyoshima et al., 1990); or (3) low catalytic activity of PLC due to mutation of the enzyme catalytic site (Yoon et al., 2004).

\section{A reduction of PLC expression strongly suppresses light excitation under low $\mathrm{Ca}^{2+}$ conditions}

We first tested the PLC deficient mutant norp $A^{P 57}$, showing normal $\mathrm{G}_{\mathrm{q}} \alpha$ (Fig. $5 C$ ) but reduced PLC expression levels (Fig. 6B). The norp $A^{P 57}$ mutant, carries a single missense mutation (Table 
A wT

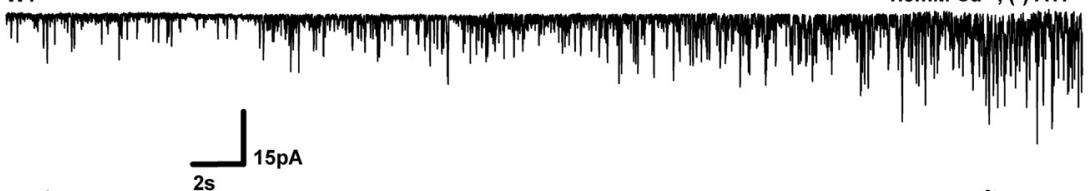
$G_{q} \alpha^{\prime}$ $T$

B

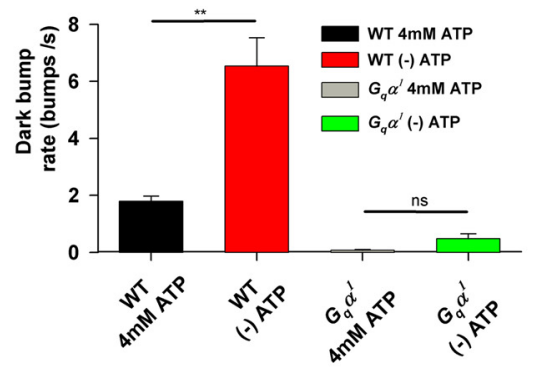

D
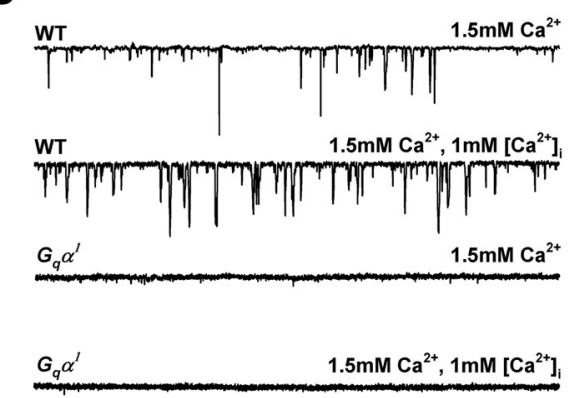

C

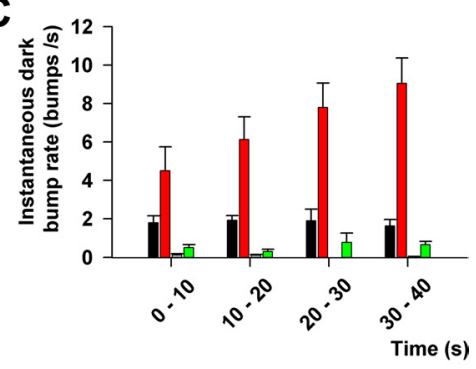

$\mathbf{E}$

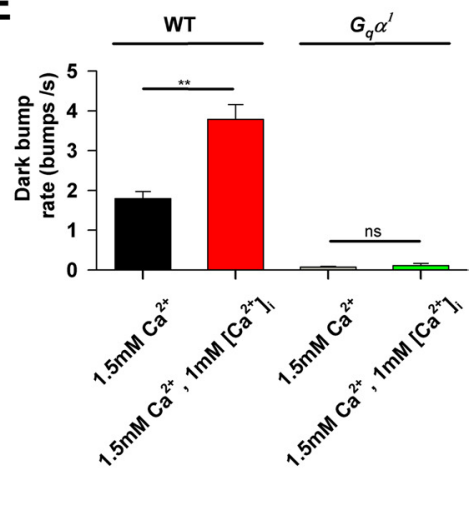

$\mathbf{F}$

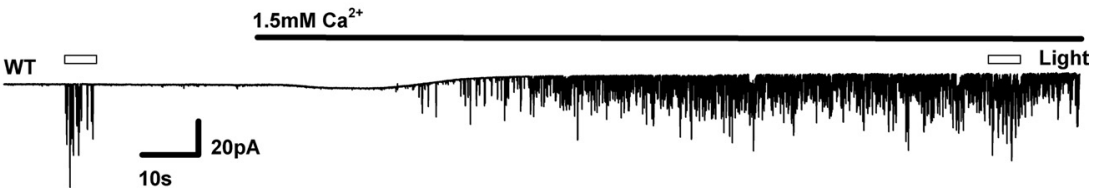

Figure 4. Dark bump activity is dramatically increased when omitting ATP from the recording pipette or by increasing intracellular $\mathrm{Ca}^{2+}$. $\boldsymbol{A}$, Dark bump activity from WT and $\mathrm{G}_{q} \alpha^{7}$ mutant flies using $1.5 \mathrm{~mm} \mathrm{Ca}{ }^{2+}$ containing extracellular solution and pipette solution with no ATP. Note that in WT flies both the rate and amplitude are increased through time, while in $G_{q} \alpha^{1}$ mutant flies dark bumps are scarce. $B$, Histogram plotting the mean bump rate with $4 \mathrm{~mm}$ ATP and without ATP in the recording pipette of WT and $G_{q} \alpha^{7}$ mutant flies (the color code applies also to $C$ and $D, n=4$, mean $\pm \mathrm{SEM}$, ${ }^{* *} p<0.01$; ns, not significant, $p>0.05$ ). C, Histogram plotting the mean instantaneous dark bump rate with 4 mu ATP and without ATP of 10 s intervals $(n=4$, mean \pm SEM). Note the increase in the mean instantaneous dark bump rate in WT flies when ATP is omitted from the recording pipette solution while, no change in the instantaneous dark bump rate when $4 \mathrm{~mm}$ ATP is added to the recording pipette solution. $\boldsymbol{D}$, Dark bump rate is increased when adding $1 \mathrm{mM} \mathrm{Ca}^{2+}$ to the recording pipette solution under $1.5 \mathrm{~mm}$ external $\mathrm{Ca}^{2+}$ conditions compared with normal pipette solution. $\boldsymbol{E}$, Histogram plotting the mean bump rate with $1 \mathrm{~mm}$ and without $\mathrm{Ca}^{2+}$ in the recording pipette $\left(n=4\right.$, mean $\pm \mathrm{SEM},{ }^{* *} p<0.01 ; \mathrm{nS}$, not significant, $p>0.05)$. $\boldsymbol{F}$, Whole-cell recordings from WT flies under low $\mathrm{Ca}^{2+}$ condition and the effect of perfusion with $\mathrm{Ca}^{2+}$ containing extracellular solution. Quantum bumps produced by light stimulation of $10 \mathrm{EP} / \mathrm{s}$ at both conditions is also demonstrated. Note that no dark activity is seen under low $\mathrm{Ca}^{2+}$ conditions while a response to light stimulation is observed. In extracellular solution containing $1.5 \mathrm{~mm} \mathrm{Ca}^{2+}$, dark bumps appear at a higher than normal rate and a light response can hardly be detected. Also note that addition of $1.5 \mathrm{~mm} \mathrm{Ca}^{2+}$ induced a small outward current due to temporary reverse activation of the electrogenic $\mathrm{Na}^{+}-\mathrm{Ca}^{2+}$ exchanger, which transports $\mathrm{Ca}^{2+}$ into the cell.

3), in the C2 domain of PLC. This mutation largely affects the PLC protein expression level ( $\sim 13 \%$ of WT, Fig. $6 B)$, but it also may affect PLC catalytic activity (Pearn et al., 1996). In the nor$p A^{P 57}$ mutant at $1.5 \mathrm{~mm}$ external $\mathrm{Ca}^{2+}$, dark bump activity was observed with a similar rate and a slight $(25 \%)$ reduction of mean peak amplitude compared with WT (Fig. 6C). Accordingly, the appearance of dark bumps in the norp $A^{P 57}$ mutant implies that the reduced PLC catalytic activity is still high enough to allow bump production by single $\mathrm{G}_{\mathrm{q}} \alpha$ activation at $1.5 \mathrm{~mm}$ external $\left[\mathrm{Ca}^{2+}\right]$. Moreover, low $\mathrm{Ca}^{2+}$ conditions abolished the appearance of dark bumps, while the addition of $1 \mathrm{mM} \mathrm{Ca}^{2+}$ into the recording pipette resulted in the reappearance of the dark bumps (Fig. 6C) similar to WT (Figs. $2 B, 3)$. Nevertheless, this mutant shows significant reduction in mean amplitude of light-induced bumps (Hardie et al., 2002). Therefore, we examined the effect of reduced external $\left[\mathrm{Ca}^{2+}\right]$ on the $R-\log I$ curve of this mutant relative to WT flies (Fig. 6D,E). In contrast to WT flies (Fig. $5 A, B)$, in the norp $A^{P 57}$ mutant, removal of external $\mathrm{Ca}^{2+}$ from the bathing solution dramatically reduced the response amplitudes at all light intensities and shifted the $R-\log I$ curve to much higher light intensities. On the other hand, addition of $1 \mathrm{mM} \mathrm{Ca}^{2+}$ to the recording pipette under low $\mathrm{Ca}^{2+}$ conditions rescued the effect of external $\mathrm{Ca}^{2+}$ removal in this mutant (Fig. $6 D, E$ ), thus showing that $\mathrm{Ca}^{2+}$ is a limiting factor for inducing the response to light under these conditions.

Low catalytic activity of PLC due to a mutation in the catalytic site eliminates dark bumps in the presence of $\mathrm{Ca}^{2+}$ and strongly suppresses light excitation in the absence of $\mathrm{Ca}^{2+}$

To support the notion that a critical level of PLC catalytic activity is required for production of a dark bump, we used another PLC defective mutant, the $n o r p A^{H 43}$. This mutant features normal $\mathrm{G}_{\mathrm{q}} \alpha$ expression levels (Fig. 5C) and modestly reduced PLC expression levels (Fig. $6 B)$, yet highly reduced PLC catalytic activity compared with WT (Yoon et al., 2004). The norp $A^{H 43}$ mutant fly, carries two missense mutations (Table 3), which are located at the X-box catalytic domain and close to the C-terminal end of the protein, respectively. In contrast to WT and the norpA $A^{P 57}$ mutant, the norp $A^{H 43}$ mutant barely exhibited dark bumps either in $1.5 \mathrm{mM} \mathrm{Ca}^{2+}$ containing extracellular solution or in the same extracellular solution with $1 \mathrm{mM} \mathrm{Ca}^{2+}$ in the recording pipette (Fig. 7A). This result indicates that a critical level of PLC activity is required for dark bump production. Moreover, the amplitude and rate of the light-induced bumps in norp $A^{H 43}$ flies were highly reduced compared with WT (Fig. $7 B, C$ ). Figure $7 C$ shows an amplitude distribution histogram of dark bumps and quantum bumps of WT vs quantum bumps of the nor$p A^{H 43}$ mutant. The quantum bumps of the norp $A^{H 43}$ mutant were similar in size to WT dark bumps and their rate was low 


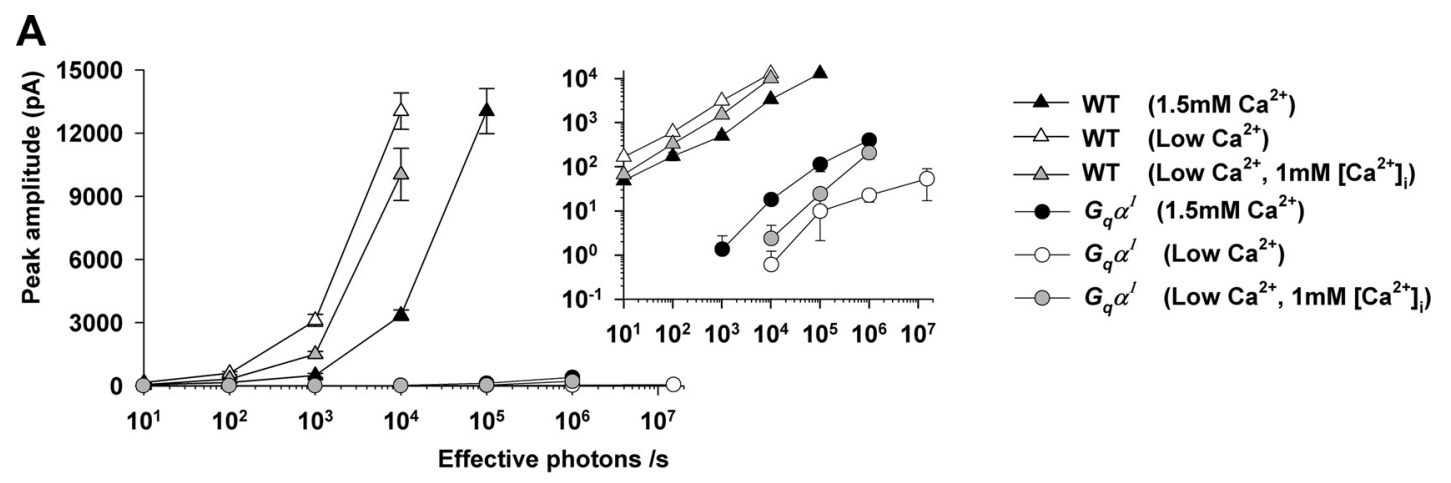

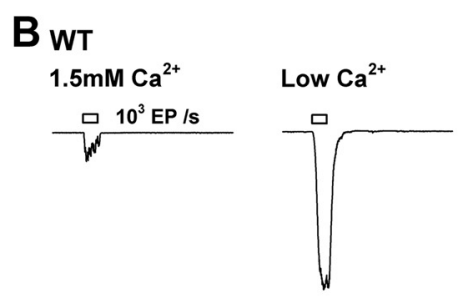

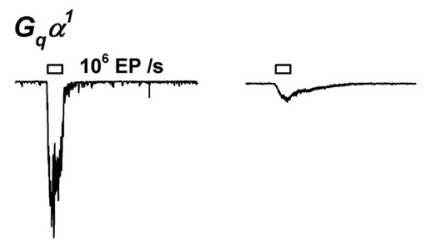

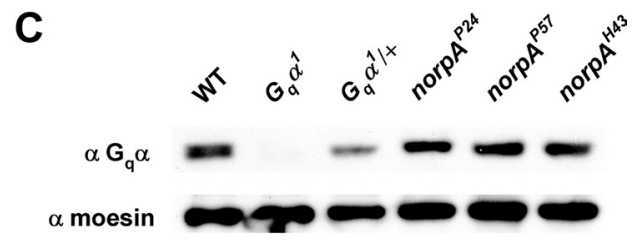
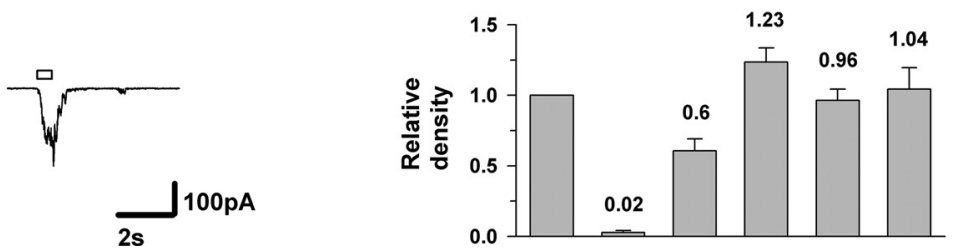

Figure 5. The $\mathrm{G}_{\mathrm{q}} \alpha^{1}$ mutant fly shows highly reduced sensitivity to light at low $\mathrm{Ca}^{2+}$ compared with $1.5 \mathrm{~mm} \mathrm{Ca}{ }^{2+}$ conditions. $A$, Intensity-response $(R-\log /)$ relationship of WT (triangles) and $\mathrm{G}_{q} \alpha^{1}$ mutant (circles) flies under low $\mathrm{Ca}^{2+}, 1.5 \mathrm{~mm} \mathrm{Ca}{ }^{2+}$ and under low $\mathrm{Ca}^{2+}$ conditions with $1 \mathrm{~mm} \mathrm{Ca}{ }^{2+}$ in the recording pipette solution. Note that the WT ( $\left.R-\log /\right)$ relationship was shifted to the left when measured under low $\mathrm{Ca}^{2+}$ conditions compared with $1.5 \mathrm{~mm} \mathrm{Ca}^{2+}$ while, $R-\log /$ relationship of the $G_{q} \alpha^{1}$ mutant was shifted to the right. Addition of $1 \mathrm{~mm} \mathrm{Ca}^{2+}$ to the recording pipette solution partially rescued the low sensitivity of the $G_{q} \alpha^{7}$ under low $\mathrm{Ca}^{2+}$ conditions. Moreover, note that at extremely high intensities of $1.5 \times 10^{7} \mathrm{EP} / \mathrm{s}$ under low $\mathrm{Ca}^{2+}$ condition the response amplitude of $G_{q} \alpha^{7}$ photoreceptors is very small. Inset: Intensity-response $(\log R-\log /)$ relationship $(n=5$, mean $\pm S E M)$. $B$, A representative light-induced response of WT and $G_{q} \alpha^{7}$ mutant to $10^{3}$ and $10^{6} \mathrm{EP} / \mathrm{s}$ respectively, under $1.5 \mathrm{~mm} \mathrm{Ca}{ }^{2+}$, low $\mathrm{Ca}^{2+}$ and under low $\mathrm{Ca}^{2+}$ conditions with $1 \mathrm{~mm} \mathrm{Ca}^{2+}$ in the recording pipette solution. $\boldsymbol{C}$, Western blot analysis of heads homogenate of dark raised WT, $G_{q} \alpha^{1}, G_{q} \alpha^{1} /+$ and norpA mutant alleles $\left(\right.$ norpA $^{P 24}$, norpA ${ }^{P 57}$, norpA ${ }^{H 43}$ ) using specific Drosophila antibodies for $\mathrm{G}_{q} \alpha$ and MOESIN as indicated. Bottom panel shows a histogram plotting the relative density of the corresponding $G_{q} \alpha$ bands of the different fly strains ( $n=3$, mean \pm SEM).

(7.6 pA, 1.7 bumps/s in the norp $A^{H 43}$ mutant, $7.4 \mathrm{pA}$ in WT dark and $22.6 \mathrm{pA}, 6.6 \mathrm{bumps} / \mathrm{s}$ in WT light). The low rate of bump production in the PLC mutant indicates that there is a low probability that photon activation of several PLC molecules would reach the minimal PLC catalytic activity level required for bump production (see model in Fig. 6A). The similarity in bump amplitude of mutant quantum bumps and WT dark bumps indicates that the integrated PLC activity of several mutant PLCs can reach the catalytic activity level of a single WT PLC molecule. These results strongly support the notion that a critical level of PLC activity is required for any kind of bump production.

These findings were further corroborated by measuring the $\mathrm{Ca}^{2+}$ dependence of the macroscopic response to light of the norp $A^{H 43}$ mutant. In this mutant, removing external $\mathrm{Ca}^{2+}$ from the bathing solution dramatically reduced the amplitude of the LIC at all light intensities and shifted the $R-\log I$ curve to much higher light intensities (Fig. 7D). Addition of $1 \mathrm{mM} \mathrm{Ca}^{2+}$ into the pipette under low external $\mathrm{Ca}^{2+}$ conditions, rescued the LIC, thus indicating that $\mathrm{Ca}^{2+}$ is a limiting factor for maintaining excitation in this mutant (Fig. $7 E$ ). Hence, Figure 7, $D$ and $E$, shows that further reduction of the already low mutant PLC catalytic activity via $\mathrm{Ca}^{2+}$ reduction totally abolished light excitation. This result is also consistent with the requirement for a minimal level of PLC catalytic activity to produce a quantum bump.
Dark bump suppression by replacing $\mathrm{Ca}^{2+}$ with $\mathrm{Mg}^{2+}, \mathrm{Sr}^{2+}$ or $\mathrm{Ba}^{2+}$

The regulation of PLC catalytic activity by $\mathrm{Ca}^{2+}$ has been thoroughly investigated. These studies show that the positive charge of $\mathrm{Ca}^{2+}$ is used to counterbalance local negative charges formed in the active site during the course of the catalytic reaction. Accordingly, $\mathrm{Ca}^{2+}$ performs electrostatic stabilization of both the substrate and the transition state, thus providing a twofold contribution to lower the activation energy of the enzyme reaction (Essen et al., 1997). However, only a few studies have addressed the cation selectivity of PLC catalytic activity. Nevertheless, these studies have indicated that replacing $\mathrm{Ca}^{2+}$ with other group IIA divalent cations (e.g., $\mathrm{Mg}^{2+}, \mathrm{Sr}^{2+}$ and $\mathrm{Ba}^{2+}$ ) reduces the catalytic activity of the enzyme (Schwertz et al., 1987; Yotsushima et al., 1993).

Several stages of bump generation require $\mathrm{Ca}^{2+}$. Therefore, it is unclear whether low $\mathrm{Ca}^{2+}$ conditions affect bump production at the PLC level by reducing its catalytic activity. To isolate a $\mathrm{Ca}^{2+}$ specific stage, it might be useful to examine the effects of other divalent cations on dark bump production. We therefore examined the effect of $\mathrm{Ca}^{2+}$ substitution with $\mathrm{Mg}^{2+}, \mathrm{Sr}^{2+}$ or $\mathrm{Ba}^{2+}$ on dark bump rate. Strikingly, none of these ion substitutions induced dark bump activity (Fig. $8 A, B$ ), consistent with previously described reduced PLC catalytic activity in the presence of these cations. Therefore, Figures 7 and 8 together indicate that $\mathrm{Ca}^{2+}$ 
A

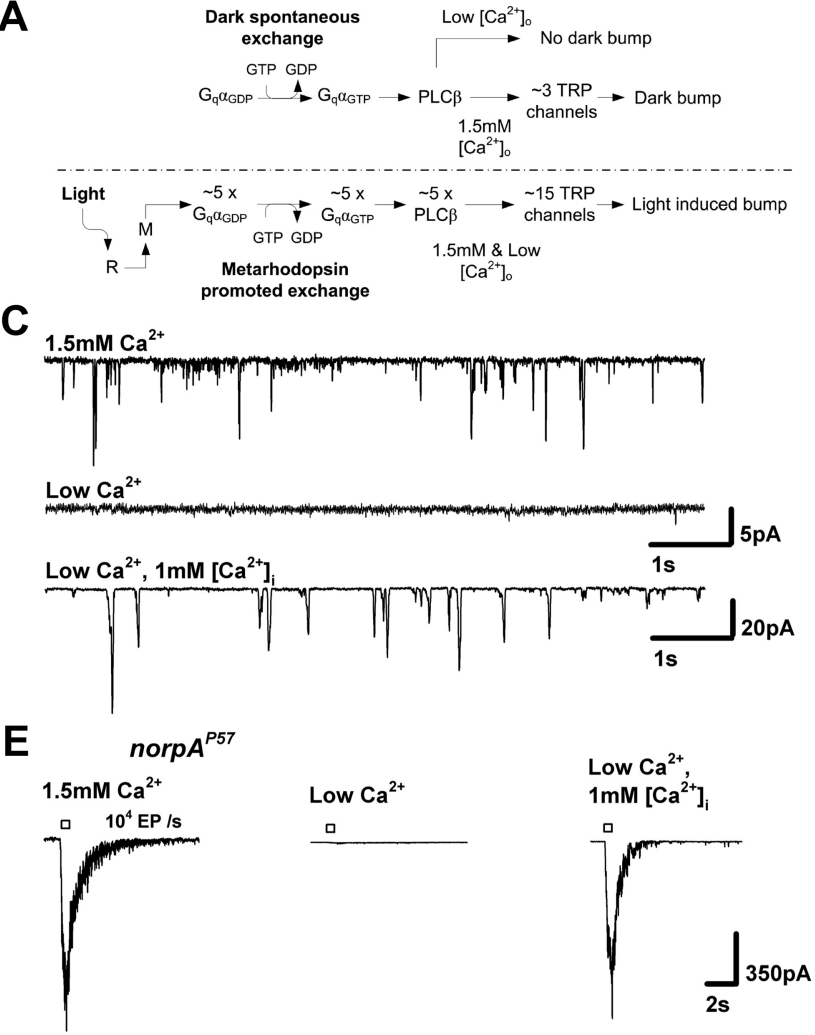

B
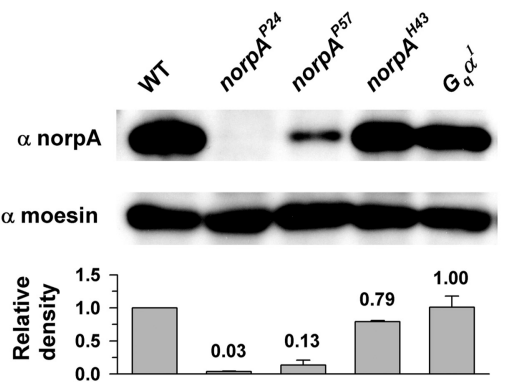

D

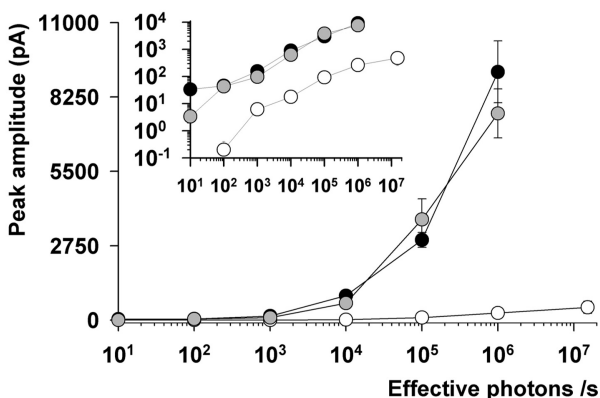

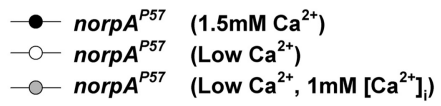

Figure 6. The norpA $A^{P 57}$ hypomorph show highly reduced light sensitivity under low $\mathrm{Ca}^{2+}$ conditions compared with $1.5 \mathrm{~mm} \mathrm{Ca}^{2+}$. $A$, A model of the initial stages of phototransduction underlying dark bump production (top) and quantum bump production (bottom). $\boldsymbol{B}$, Western blot analysis of heads homogenate of dark raised WT, norpA mutant alleles (norp $A^{P 24}$, norp $A^{P 57}$, norp $A^{H 43}$ ) and $G_{q} \alpha^{1}$ mutant using specific Drosophila antibodies for NORPA and MOESIN as indicated. Bottom panel shows a histogram plotting the relative density of the corresponding NORPA bands of the different fly strains $\left(n=3\right.$, mean \pm SEM). C, Dark bumps are observed in norpA ${ }^{P 57}$ at total darkness under $1.5 \mathrm{~mm} \mathrm{Ca}^{2+}$ conditions (top trace). Low $\mathrm{Ca}^{2+}$ condition abolished the dark activity (middle trace). Addition of $1 \mathrm{mmCa}{ }^{2+}$ to the recording pipette solution resulted in the reappearance of dark bumps under low $\mathrm{Ca}^{2+}$ conditions (bottom trace) $(n=4)$. $\boldsymbol{D}$, Intensity-response $(R-\log /)$ relationship of $n o r p A^{P 57}$ mutant flies under low $\mathrm{Ca}^{2+}, 1.5 \mathrm{~mm} \mathrm{Ca}^{2+}$ and under low $\mathrm{Ca}^{2+}$ conditions with $1 \mathrm{~mm} \mathrm{Ca}^{2+}$ in the recording pipette solution. Note that under low $\mathrm{Ca}^{2+}$ conditions drastically reduced the light response, compared with $1.5 \mathrm{~mm} \mathrm{Ca}{ }^{2+}$ while addition of $1 \mathrm{~mm} \mathrm{Ca}^{2+}$ to the recording pipette solution rescued the low sensitivity under low $\mathrm{Ca}^{2+}$ conditions. Moreover, note that at extremely high intensities of $1.5 \times 10^{7} \mathrm{EP} / \mathrm{s}$ under low $\mathrm{Ca}^{2+}$ conditions the response amplitude of norpA ${ }^{P 57}$ photoreceptors are very small. Inset: Intensity-response (logR-log/) relationship $\left(n=5\right.$, mean \pm SEM). $E$, A representative light-induced responses of norpA ${ }^{P 57}$ mutant to $10^{4} \mathrm{EP} / \mathrm{s}$ under $1.5 \mathrm{~mm} \mathrm{Ca}^{2+}$, low Ca ${ }^{2+}$ and under low $\mathrm{Ca}^{2+}$ conditions with $1 \mathrm{~mm} \mathrm{Ca}{ }^{2+}$ in the recording pipette solution.

Table 3. Details of the various alleles used in this study

\begin{tabular}{|c|c|c|c|c|}
\hline Allele & Description & Total protein level (\% WT) & Specific PLC activity (\% WT) & Reference \\
\hline$w^{1118}(\mathrm{WT})$ & White eyed & & & \\
\hline$G \alpha q^{1}\left(\mathrm{G}_{q} \alpha^{1}\right)$ & $\begin{array}{l}\text { Splice acceptor site leading to in-frame } \\
\text { deletion of residues } 154-156\end{array}$ & $\sim 2 \%\left(\mathrm{G}_{\mathrm{q}} \alpha\right.$, Fig. $\left.5 \mathrm{C}\right)$ & - & (Scott et al., 1995) \\
\hline $\mathrm{G}_{q} \alpha^{1} / S M 6$ (heterozygote, $G_{q} \alpha^{1} /+$ ) & & $\sim 60 \%\left(\mathrm{G}_{\mathrm{q}} \alpha\right.$, Fig. $\left.5 \mathrm{C}\right)$ & - & \\
\hline$G \beta e^{1} / T M 6 B$ (heterozygote, $G \beta e^{1} /+$ ) & Cys293Tyr & $\sim 50 \%\left(\mathrm{G}_{\mathrm{g}} \beta\right)$ & - & (Dolph et al., 1994; Elia et al., 2005) \\
\hline norp $A^{H 43} ;$ bw;st abbreviation: norp $A^{H 43}$ & Ser347Asn and Thr1007Ser & $\sim 79 \%$ (PLC, Fig. 6B) & $\sim 8 \%$ & (Yoon et al., 2004) \\
\hline norpA $A^{P 57} ; b w ; s t$ abbreviation: norp $A^{P 57}$ & Gly768Asp & 〜13\% (PLC, Fig. 6B) & $\sim 27 \%$ & (Pearn et al., 1996; Yoon et al., 2004) \\
\hline
\end{tabular}

facilitates dark bump production by increasing the catalytic activity of PLC.

The $\mathrm{Ca}^{2+}$ dependence of quantum bump shape is determined downstream of PLC

The $\mathrm{Ca}^{2+}$ dependence of PLC activity, in general, and of fly eye PLC (NORPA) in particular has been reported (Toyoshima et al., 1990; Running Deer et al., 1995; Essen et al., 1997; Hardie, 2005). In Drosophila, both in vivo and in vitro measurements revealed $\mathrm{Ca}^{2+}$ dependence of PLC activity. This activity shows a bell-shaped dependence of $\mathrm{PIP}_{2}$ hydrolysis on $\left[\mathrm{Ca}^{2+}\right]$, with maximal basal activity in the range of $10^{-7}-10^{-5} \mathrm{M}\left[\mathrm{Ca}^{2+}\right]$ (Toyoshima et al., 1990; Running Deer et al., 1995; Hardie, 2005).
Previous studies have shown a strong $\mathrm{Ca}^{2+}$-dependent facilitation of bump kinetics (Henderson et al., 2000), which may arise from either a facilitation of PLC activity or from a $\mathrm{Ca}^{2+}$. dependent increase of channel sensitivity to a PLC product (Hardie and Postma, 2008). The study of the norp $A^{H 43}$ mutant revealed an important phenomenon: Although the PLC catalytic activity in this mutant is very low, the waveform and time to peak of the quantum bumps were virtually unaffected by the mutation (Fig. 9A,B). This result clearly demonstrates that the effect of low $\mathrm{Ca}^{2+}$ on response kinetics is PLC independent and operates downstream of PLC activity. This conclusion was further supported by experiments in which $\mathrm{Ca}^{2+}$ was replaced by $\mathrm{Sr}^{2+}$ and $\mathrm{Ba}^{2+}$ (Fig. 9C,D). Although dark bump production was suppressed under these conditions, quantum bump kinetics were 
A

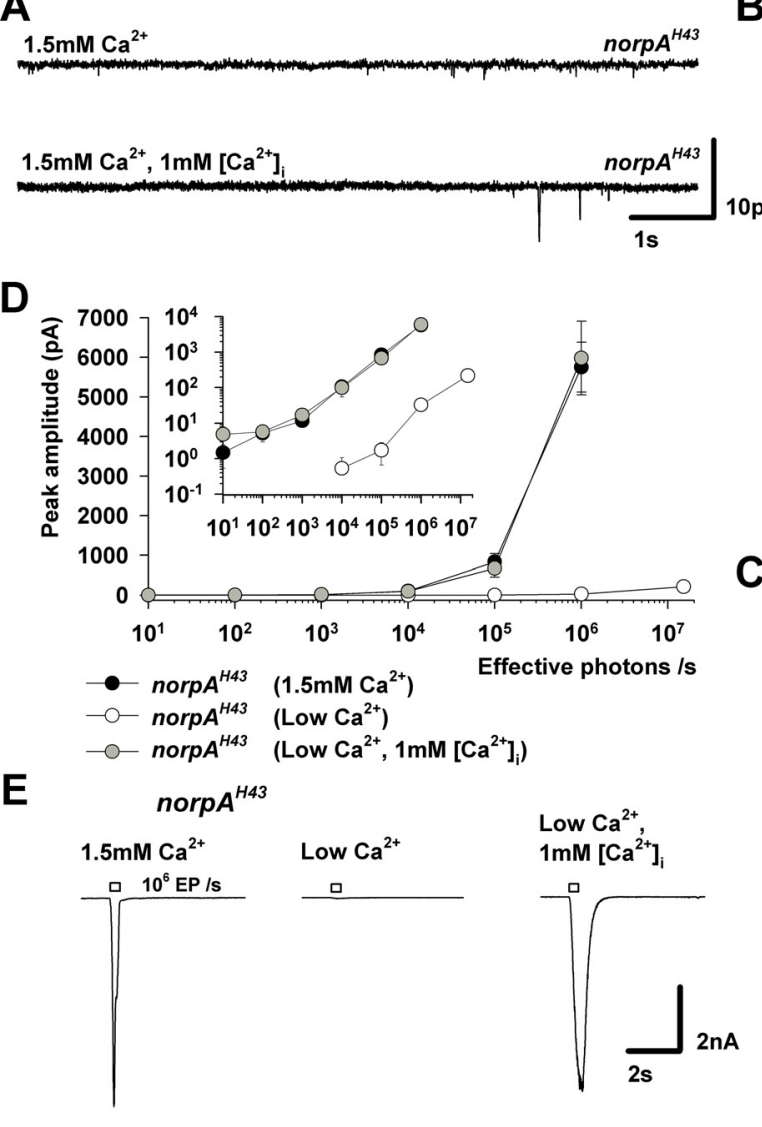

B

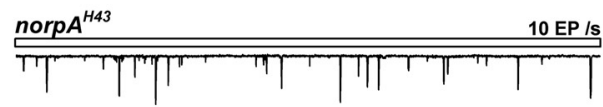

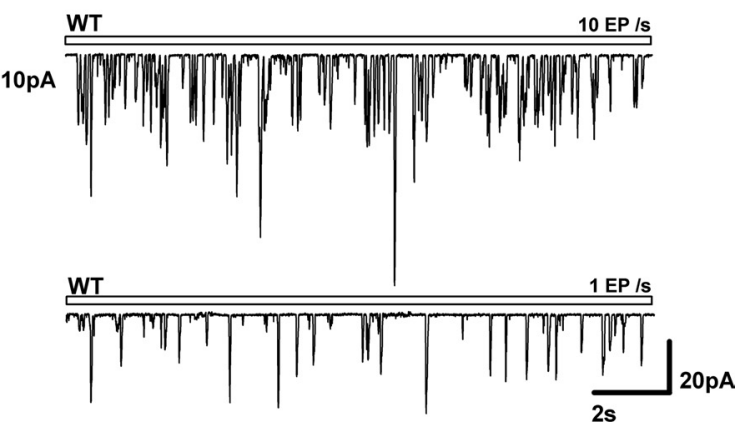

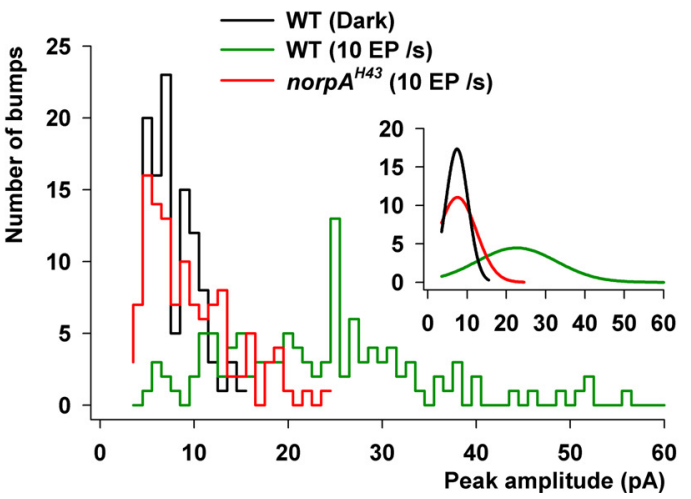

Figure 7. The norp ${ }^{H 43}$ mutant with low PLC catalytic activity shows no dark bumps, reduced quantum bump rate and amplitude, and a highly reduced sensitivity to light under low $\mathrm{Ca}^{2+}$ conditions. $A$, Dark bumps are not observed in norp $A^{H 43}$ at total darkness under $1.5 \mathrm{~mm} \mathrm{Ca}^{2+}$ conditions (top trace) and under $1.5 \mathrm{~mm} \mathrm{Ca}^{2+}$ conditions with the addition of $1 \mathrm{~mm} \mathrm{Ca}{ }^{2+}$ to the patch-pipette solution (bottom trace) $(n=4)$. $B$, Light-induced bumps in norpA ${ }^{H 43}$ mutant flies in response to light intensity of $10 \mathrm{EP} / \mathrm{s}$ (top trace) and in WT flies to light intensities of $10 \mathrm{EP} / \mathrm{s}$ (middle trace) and $1 \mathrm{EP} / \mathrm{s}$ (bottom trace) $(n=4)$. Note that the light-induced bumps of the mutant are small, while their kinetics are as fast as those of WT bumps. C, Histogram plotting distribution of bump amplitude of WT dark bumps, WT quantum bumps and norp $A^{\text {H43 }}$ quantum bumps $(n=117)$. Inset, Gaussian fits to the amplitude distribution histograms (mean peak amplitude; WT dark $=7.4$ $\mathrm{pA}$, WT light $=22.6 \mathrm{pA}$ and norpA ${ }^{H 43}$ light $\left.=7.6 \mathrm{pA}\right) \cdot \boldsymbol{D}$, Intensity-response $(R-\log /)$ curve of norpA ${ }^{H 43}$ mutant flies under low $\mathrm{Ca}^{2+}, 1.5 \mathrm{~mm} \mathrm{Ca}^{2+}$ and under low $\mathrm{Ca}^{2+}$ conditions with $1 \mathrm{~mm} \mathrm{Ca}{ }^{2+}$ in the recording pipette solution. Note that even at extremely high intensities of $1.5 \times 10^{7} \mathrm{EP} / \mathrm{s}$ under low $\mathrm{Ca}^{2+}$ conditions the response amplitude of norp $\mathrm{A}^{\mathrm{H} 43}$ photoreceptors was very small. Inset, Intensity-response $(\log R-\log /)$ relationship $\left(n=5\right.$, mean \pm SEM). $E$, A representative light-induced response to $10^{6} \mathrm{EP} / \mathrm{s}$ in norp $A^{\mathrm{H43}}$ mutant under low $\mathrm{Ca}^{2+}, 1.5 \mathrm{~mm} \mathrm{Ca}^{2+}$, and under low $\mathrm{Ca}^{2+}$ conditions with $1 \mathrm{~mm} \mathrm{Ca}^{2+}$ in the recording pipette solution.

only slightly slowed down. The fact that $\mathrm{Sr}^{2+}$ or $\mathrm{Ba}^{2+}$ substitute $\mathrm{Ca}^{2+}$ in accelerating bump kinetics, but do not substitute $\mathrm{Ca}^{2+}$ in rescuing dark bump generation is important because it strongly suggests that a second site of $\mathrm{Ca}^{2+}$ action exists. In contrast to $\mathrm{Sr}^{2+}$ and $\mathrm{Ba}^{2+}$, substituting $\mathrm{Ca}^{2+}$ with $\mathrm{Mg}^{2+}$ drastically slowed down the kinetics of the quantum bumps and macroscopic response (Figs. 8C, 9C). This result suggests that unlike $\mathrm{Sr}^{2+}$ and $\mathrm{Ba}^{2+}, \mathrm{Mg}^{2+}$ cannot substitutes $\mathrm{Ca}^{2+}$ in accelerating bump kinetics. Altogether, these observations strongly suggest that $\mathrm{Ca}^{2+}$ operates in at least two stages of bump production: (1) as a unique cofactor in PLC catalytic activity that cannot be replaced by other divalent cations; (2) as a factor required for the fast kinetics of synchronous channel activation that operates downstream of PLC and can be substituted by $\mathrm{Sr}^{2+}$ and $\mathrm{Ba}^{2+}$ but not by $\mathrm{Mg}^{2+}$.

\section{Discussion}

Drosophila flies are mainly active during medium intensities of ambient lights at dusk and dawn (Rieger et al., 2007). At these light intensities, arriving photons are absorbed by different microvilli of a single photoreceptor cell. Each of these $\sim 30,000 \mathrm{mi}-$ crovilli functions as an independent unit, producing a single quantum bump, while the cell membrane integrates all bumps
(Hardie and Raghu, 2001). A high rate of dark bumps, results in their temporal summation, which may reach quantum bump amplitude and hamper single-photon detection (Figs. $2 \mathrm{~B}$, arrows, 4F). A similar example of spontaneous G-protein activation comes from a study in yeasts, showing receptor independent spontaneous G-protein activation when a GAP was genetically eliminated. This leads to spontaneous activation of the G-proteinmediated mating pathway at levels normally seen upon receptor activation (Siekhaus and Drubin, 2003). Accordingly, suppression of the G-protein-dependent spontaneous activation of mating in yeasts occurs by accelerating the GTPase reaction. The two studies show that the high fidelity of G-protein-mediated signaling systems relies on suppression of background noise induced by receptor independent activity of the G-proteins.

Suppression of dark noise by a PLC-mediated mechanism In this work we show that in Drosophila under physiological conditions the mechanism underlying false signaling suppression is partially concealed but can be readily exposed by mutations or nonphysiological conditions. Using the single-photon responses and dark bumps of Drosophila mutant flies facilitated the discovery of the mechanism underlying suppression of dark noise at the single molecule level in vivo. The mechanism underlying dark 
A

Dark

Low $\mathrm{Ca}^{2+}$

$1.5 \mathrm{mM} \mathrm{Mg}^{2+}$

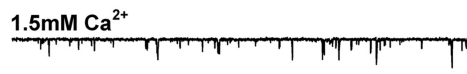

$1.5 \mathrm{mM} \mathrm{Sr}{ }^{2+}$

$1.5 \mathrm{mM} \mathrm{Ba}^{2+}$

B

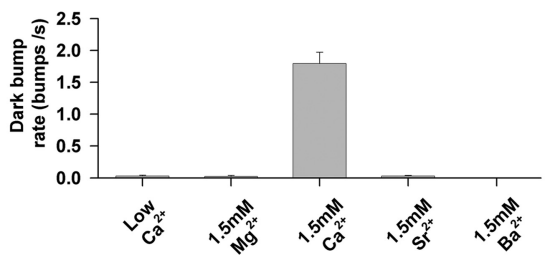

C
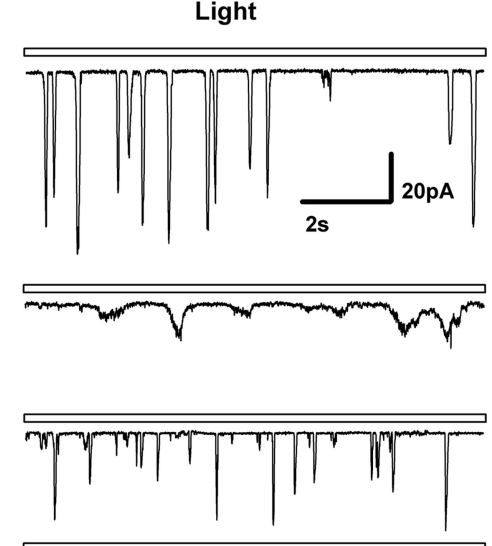

"

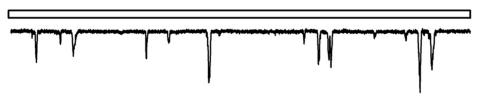

D

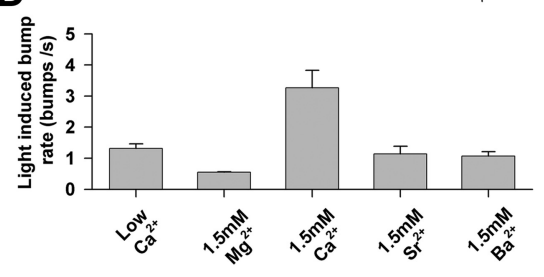

Figure 8. Group IIA divalent cations $\mathrm{Mg}^{2+}, \mathrm{Sr}^{2+}$, and $\mathrm{Ba}^{2+}$ do not induce dark bumps. $A$, Whole-cell recordings from WT photoreceptors at total darkness at the various conditions as indicated. Note that only $\mathrm{Ca}^{2+}$ induced dark bump activity. $\boldsymbol{B}$, Histogram plotting the mean bump rate of dark bumps at the different conditions $(n=4$, mean \pm SEM). C, Light response to $1 \mathrm{EP} / \mathrm{s}$ intensity. Note that in all cases bumps can be induced by the light stimuli. $\boldsymbol{D}$, Histogram plotting the mean bump rate of lightinduced bumps at the different conditions ( $n=4$, mean \pm SEM).

bump suppression and reliable quantum bump production relies on the requirement for a crucial level of PLC activity that is necessary for bump production. Accordingly, activation of a single PLC molecule has a low probability of producing a bump, as manifested by the low rate of dark bumps even when a high rate of spontaneous $\mathrm{G}_{\mathrm{q}} \alpha$ activation exists. On the other hand, photoninduced synchronized activation of several neighboring $\mathrm{G}_{\mathrm{q}} \alpha$ molecules, which activate several PLC molecules, has a high probability of producing a bump. This mechanism leads to at least $85 \%$ suppression of dark bump activity under physiological conditions.

The crucial finding, which supports the notion that a certain minimal level of integrated PLC catalytic activity is required for bump production came from the study of the norp $A^{H 43}$. This mutant has nearly normal PLC expression levels but $\sim 10$-fold reduction in enzymatic catalytic activity relative to WT. In this mutant there is no production of dark bumps and both the rate and amplitude of the quantum bumps are highly reduced. Interestingly, the amplitude distribution of the mutant quantum bumps was similar to that of WT dark bumps (Fig. 7C). These observations show that the level of PLC catalytic activity is the critical parameter for triggering bump production because the only difference between the mutant and WT flies is the mutant's reduced catalytic activity. Accordingly, the activated single mutant PLC molecule with low catalytic activity is unable to reach the required minimal level of enzymatic activity that is required for bump production, resulting in total suppression of dark bumps. Importantly, several light activated mutant PLC molecules, each with low catalytic activity as in-

dividual unit yet synchronously activated as a group, can reach the minimal level required for bump production albeit with low probability. Therefore, a reduction in both the rate and amplitude of the quantum bumps is observed under such circumstances.

An additional way to reduce PLC catalytic activity can be obtained by reducing cellular $\left[\mathrm{Ca}^{2+}\right]$, which eliminates dark bump production (Fig. $2 A$ ). In WT flies, under low $\mathrm{Ca}^{2+}$ conditions, light excitation is still maintained and quantum bumps are preserved because the integrated PLC catalytic activity is sufficient to reach the critical level for bump production. However, in the $G_{q} \alpha^{1}$ and norpA mutants, light excitation is lost at low $\left[\mathrm{Ca}^{2+}\right]$ because the integrated PLC catalytic activity is further reduced by the low $\left[\mathrm{Ca}^{2+}\right]$. This low PLC catalytic activity does not exceed the required level for bump productions.

An alternative strategy to reduce dark noise and maintain signal reliability can be obtained by large amplification of the signal. In vision, this strategy has a major drawback because the system's operating range is reduced by the large amplification. The relatively small gain $(\sim 5$-fold $)$ between photopigment activation and the G-protein stage, which is maintained throughout the fly phototransduction cascade up to channel openings (Drosophila and Musca; Minke and Stephenson, 1985; Hardie et al., 2002), maintains a balance between a wide operating range required for vision and noise suppression. Hence, the existence of a nonlinearity between PLC activity and bump production enables dark noise suppression in a low gain sensory system.

\section{Suppression of dark noise by compartmentalization}

An additional mechanism that suppresses the dark noise is the specialized structure of the signaling compartment. The signaling compartment, the rhabdomere, is composed of $\sim 30,000$ tightly packed microvilli constituting an integral part of the plasma membrane, where the proteins of the phototransduction machinery reside. The confinement of the phototransduction machinery into identical and separated topological segments, divides the extremely high protein expression level into diminutive amounts of functional groups. This division reduces the possibility of integration and suppresses dark noise. By adding a "gate keeper", in the form of nonlinearity between PLC activity and bump production, spontaneous activity can be further reduced while concomitantly increasing the signal-to-noise ratio. The functional segregation of individual microvilli was revealed in the $G_{q} \alpha^{1}$, norp $A^{P 57}$ and norp $A^{H 43}$ mutants under low $\mathrm{Ca}^{2+}$ conditions, when responses to light were virtually eliminated. This response suppression was apparent even at extremely high light intensities of $1.5 \times 10^{7}$ effective photons $s^{-1}$, where $\sim 50$ rhodopsin molecules are activated within each microvillus. One could expect that a summation of PLC activities among different microvilli may lead to a bump-like response, even if the activity within a single microvillus is below the critical PLC activity level 
A

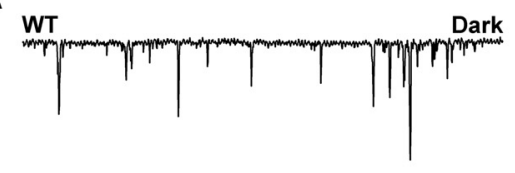

WT
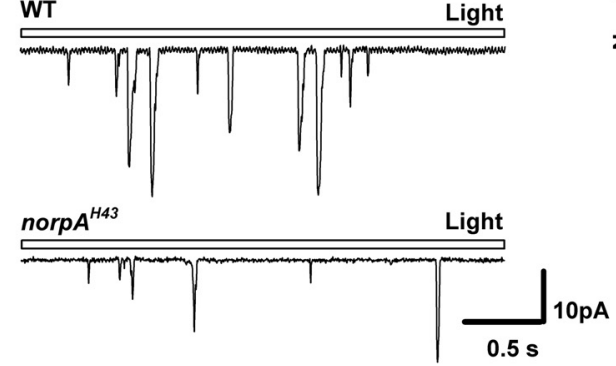

C

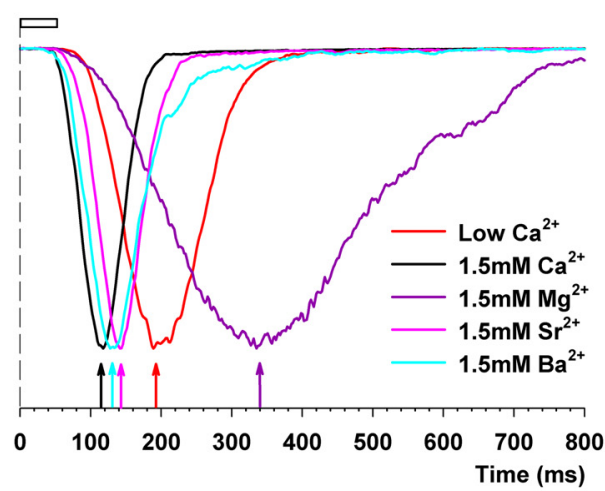

B

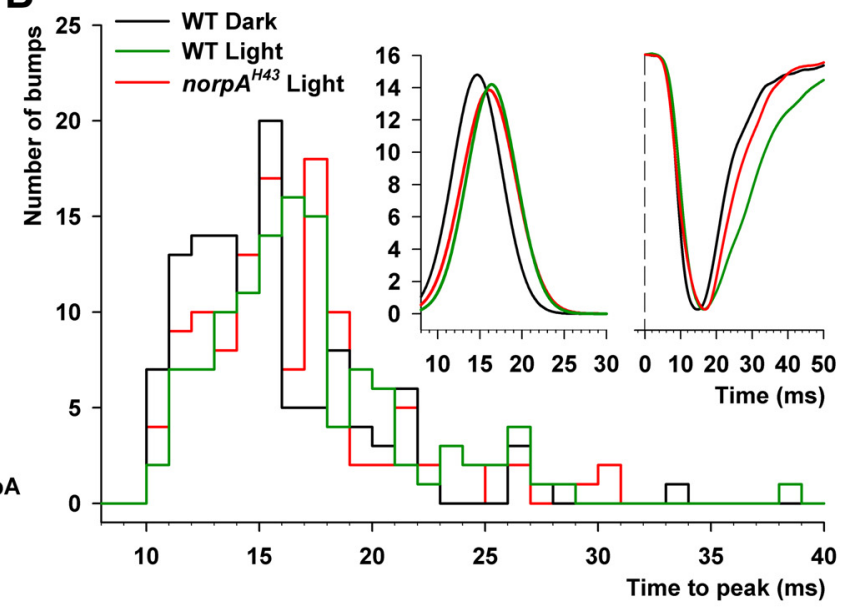

D

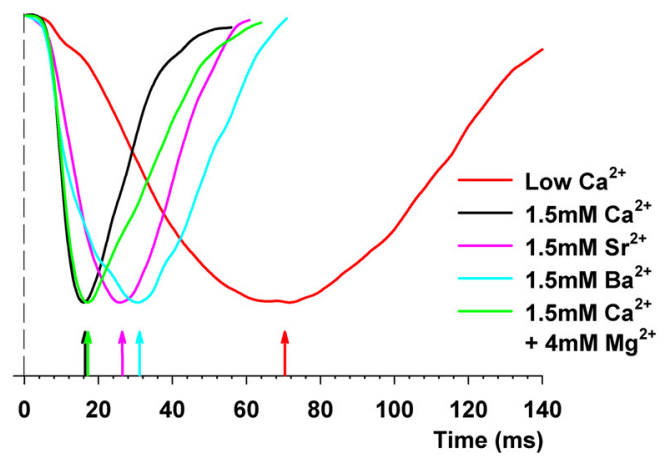

Figure 9. Bump kinetics is independent of PLC catalytic activity. $A$, Whole-cell recordings from WT photoreceptors in total darkness (top trace), light-induced bumps in WT in response to light intensity of $1 \mathrm{EP} / \mathrm{s}$ (middle trace) and light-induced bumps in norpA ${ }^{\mathrm{H} 43}$ mutant flies in response to light intensity of $10 \mathrm{EP} / \mathrm{s}$ (bottom trace). $\boldsymbol{B}$, Histogram plotting the time to peak ( $t_{\mathrm{p}}$ ) distribution of WT dark bumps, WT

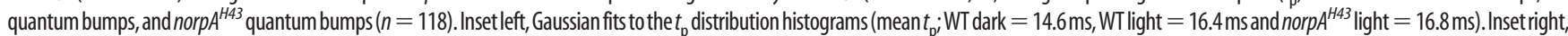
Normalized average of 118 bumps from traces in A $\left(t_{p} ;\right.$ WT dark $=14.7 \mathrm{~ms}$, WT light $=16.4 \mathrm{~ms}$ and norp $A^{\text {H43 }}$ light $\left.=16.1 \mathrm{~ms}\right)$. C, Light response to a brief 50 ms flash at the various group IIA divalent cations solutions as indicated (arrows indicate the $t_{\mathrm{p}}$ of the light response, $t_{\mathrm{p}}$; Low Ca ${ }^{2+}=189 \mathrm{~ms}, 1.5 \mathrm{~mm} \mathrm{Ca}^{2+}=118 \mathrm{~ms}, 1.5 \mathrm{~mm} \mathrm{Mg}{ }^{2+}=335 \mathrm{~ms}, 1.5 \mathrm{~mm} \mathrm{Sr}{ }^{2+}=141 \mathrm{~ms}$, and $1.5 \mathrm{~mm} \mathrm{Ba}{ }^{2+}=128 \mathrm{~ms}$ ). $\boldsymbol{D}$, Normalized average of 100 bumps at the presence of various group liA divalent cations solutions as indicated (arrows indicate the $t_{\mathrm{p}}$ of the averaged quantum bump, $t_{\mathrm{p}} ; \mathrm{Low} \mathrm{Ca}^{2+}=71.5 \mathrm{~ms}, 1.5 \mathrm{~mm} \mathrm{Ca}^{2+}=$ $16 \mathrm{~ms}, 1.5 \mathrm{~mm} \mathrm{Sr}^{2+}=25.7 \mathrm{~ms}, 1.5 \mathrm{~mm} \mathrm{Ba}^{2+}=30.6 \mathrm{~ms}$ and $\left.1.5 \mathrm{~mm} \mathrm{Ca}^{2+}+4 \mathrm{~mm} \mathrm{Mg}^{2+}=17.2 \mathrm{~ms}\right)$.

necessary for bump generation. However, contrary to this expected summation, the observed response suppression in the mutants indicates a lack of summation of PLC activity among neighboring microvilli. These findings are consistent with previous suggestion that a microvillus is the minimal functional unit for producing a bump (Hamdorf and Kirschfeld, 1980; Hardie et al., 2002; Yau and Hardie, 2009).

\section{$\mathrm{Ca}^{2+}$ dependence of bump kinetics operates downstream of PLC activity}

The available data clearly indicate that the discrete nature of the bump does not arise from properties of light activated channels, because direct activation of the channels under physiological conditions by polyunsaturated fatty acid (Chyb et al., 1999) induce channel noise but not bump noise (Hardie and Minke, 1994). A question thus arises as to the mechanism underlying synchronized channel activity that produces the bump. Several observations in the current study give clues, which help identify the phototransduction stages in which synchronized channel activity is produced. Since $\mathrm{Ca}^{2+}$ is a major factor in regulation of phototransduction, a study of the $\mathrm{Ca}^{2+}$ dependence of bump kinetics, which is determined by the degree of synchronization in channel activation, may shed light on this issue.
The $\mathrm{Ca}^{2+}$ dependence of quantum bump amplitude and kinetics have several properties, including two phase initiation and very slow kinetics under low $\mathrm{Ca}^{2+}$ conditions (Henderson et al., 2000; Figs. 2, 9). Moreover, the kinetics and amplitude of the averaged bump are largely constant in a large range of external $\left[\mathrm{Ca}^{2+}\right]$ between $100 \mu \mathrm{M}$ and $1.5 \mathrm{~mm}$ (Henderson et al., 2000). A major question arises as to how and at what stage of phototransduction does $\mathrm{Ca}^{2+}$ regulate bump kinetics? Important clues have emerged from comparison of quantum bump kinetics between the norp $A^{H 43}$ mutant and WT flies, and from assays on the effects of group IIA divalent cations (Figs. 7-9). Strikingly, the kinetics of the quantum bumps recorded from the norp $A^{H 43}$ mutant was virtually normal (Fig. 9). If $\mathrm{Ca}^{2+}$ affects the bump kinetics at the stage of PLC activity, one would expect significantly slower bump kinetics in the mutant relative to WT when PLC catalytic activity is reduced by the norp $A^{H 43}$ mutation. However, our observations were to the contrary (Figs. 7, 9). This result indicates that $\mathrm{Ca}^{2+}$ affect bump kinetics downstream of PLC. The observation that quantum bump kinetics is virtually normal in the presence of $\mathrm{Sr}^{2+}$ and $\mathrm{Ba}^{2+}$, while dark bumps are eliminated (Figs. 8, 9) further support the conclusion that $\mathrm{Ca}^{2+}$ affects bump kinetics downstream of PLC. This is because the elimination of dark bumps in the presence of $\mathrm{Sr}^{2+}$ and $\mathrm{Ba}^{2+}$ is explained by reduced PLC catalytic activity, below the crucial level required for bump 
production. The accelerated kinetics of these quantum bumps relative to low $\mathrm{Ca}^{2+}$ conditions despite reduced PLC catalytic activity indicates that $\mathrm{Sr}^{2+}$ and $\mathrm{Ba}^{2+}$ can substitute for $\mathrm{Ca}^{2+}$ downstream of PLC. Accordingly, this study shed light on two different sites of $\mathrm{Ca}^{2+}$ action in the bump generating mechanism: (1) a site in which $\mathrm{Ca}^{2+}$ regulated PLC catalytic activity, (2) a site operating downstream of PLC, most likely at the channel stage. This mechanism determines the degree of synchronized channel activity in $\mathrm{Ca}^{2+}$-dependent manner.

\section{References}

Barash S, Minke B (1994) Is the receptor potential of fly photoreceptors a summation of single-photon responses? Comments Theoretical Biology 3:229-263.

Bloomquist BT, Shortridge RD, Schneuwly S, Perdew M, Montell C, Steller H, Rubin G, Pak WL (1988) Isolation of a putative phospholipase C gene of Drosophila, norpA, and its role in phototransduction. Cell 54:723-733.

Chyb S, Raghu P, Hardie RC (1999) Polyunsaturated fatty acids activate the Drosophila light-sensitive channels TRP and TRPL. Nature 397:255-259.

Cook B, Bar-Yaacov M, Cohen Ben-Ami H, Goldstein RE, Paroush Z, Selinger Z, Minke B (2000) Phospholipase C and termination of G-protein-mediated signalling in vivo. Nat Cell Biol 2:296-301.

Delgado R, Bacigalupo J (2009) Unitary recordings of TRP and TRPL channels from isolated Drosophila retinal photoreceptor rhabdomeres: activation by light and lipids. J Neurophysiol 101:2372-2379.

Devary O, Heichal O, Blumenfeld A, Cassel D, Suss E, Barash S, Rubinstein CT, Minke B, Selinger Z (1987) Coupling of photoexcited rhodopsin to inositol phospholipid hydrolysis in fly photoreceptors. Proc Natl Acad Sci U S A 84:6939-6943.

Dolph PJ, Man-Son-Hing H, Yarfitz S, Colley NJ, Deer JR, Spencer M, Hurley JB, Zuker CS (1994) An eye-specific Gb subunit essential for termination of the phototransduction cascade. Nature 370:59-61.

Elia N, Frechter S, Gedi Y, Minke B, Selinger Z (2005) Excess of Gb over $\mathrm{G}_{\mathrm{q}} \mathrm{a}$ in vivo prevents dark, spontaneous activity of Drosophila photoreceptors. J Cell Biol 171:517-526.

Essen LO, Perisic O, Katan M, Wu Y, Roberts MF, Williams RL (1997) Structural mapping of the catalytic mechanism for a mammalian phosphoinositide-specific phospholipase C. Biochemistry 36:1704-1718.

Frechter S, Elia N, Tzarfaty V, Selinger Z, Minke B (2007) Translocation of Gqa mediates long-term adaptation in Drosophila photoreceptors. J Neurosci 27:5571-5583.

Gu Y, Oberwinkler J, Postma M, Hardie RC (2005) Mechanisms of light adaptation in Drosophila photoreceptors. Curr Biol 15:1228-1234.

Hamdorf K, Kirschfeld K (1980) Reversible events in the transduction process of photoreceptors. Nature 283:859-860.

Hardie RC (1991) Whole-cell recordings of the light-induced current in dissociated Drosophila photoreceptors: evidence for feedback by calcium permeating the light-sensitive channels. Proc R Soc Lond B 245:203-210.

Hardie RC (1995) Photolysis of caged $\mathrm{Ca}^{2+}$ facilitates and inactivates but does not directly excite light-sensitive channels in Drosophila photoreceptors. J Neurosci 15:889-902.

Hardie RC (2005) Inhibition of phospholipase C activity in Drosophila photoreceptors by 1,2-bis(2-aminophenoxy)ethane $N, N, N^{\prime}, N^{\prime}$-tetraacetic acid (BAPTA) and di-bromo BAPTA. Cell Calcium 38:547-556.

Hardie RC, Minke B (1994) Spontaneous activation of light-sensitive channels in Drosophila photoreceptors. J Gen Physiol 103:389-407.

Hardie RC, Mojet MH (1995) Magnesium-dependent block of the lightactivated and trp-dependent conductance in Drosophila photoreceptors. J Neurosci 74:2590-2599.

Hardie RC, Postma M (2008) Phototransduction in microvillar photoreceptors of Drosophila and other invertebrates. In: The senses: a comprehensive reference (Allan IB, Akimichi K, Gordon MS, Gerald W, Thomas DA, Richard HM, Peter D, Donata O, Stuart F, Gary KB, Bushnell MC, Jon HK, Esther G, eds), pp 77-130. New York: Academic.

Hardie RC, Raghu P (2001) Visual transduction in Drosophila. Nature 413:186-193.

Hardie RC, Martin F, Cochrane GW, Juusola M, Georgiev P, Raghu P (2002) Molecular basis of amplification in Drosophila phototransduction. Roles for G protein, phospholipase C, and diacylglycerol kinase. Neuron 36:689-701.
Henderson SR, Reuss H, Hardie RC (2000) Single photon responses in Drosophila photoreceptors and their regulation by $\mathrm{Ca}^{2+}$. J Physiol Lond 524:179-194.

Huang J, Liu CH, Hughes SA, Postma M, Schwiening CJ, Hardie RC (2010) Activation of TRP channels by protons and phosphoinositide depletion in Drosophila photoreceptors. Curr Biol 20:189-197.

Katz B, Minke B (2009) Drosophila photoreceptors and signaling mechanisms. Front Cell Neurosci 3:2.

Kosloff M, Elia N, Joel-Almagor T, Timberg R, Zars TD, Hyde DR, Minke B, Selinger Z (2003) Regulation of light-dependent $\mathrm{Gq}_{\mathrm{a}}$ translocation and morphological changes in fly photoreceptors. EMBO J 22:459-468.

Leung HT, Tseng-Crank J, Kim E, Mahapatra C, Shino S, Zhou Y, An L, Doerge RW, Pak WL (2008) DAG lipase activity is necessary for TRP channel regulation in Drosophila photoreceptors. Neuron 58:884-896.

Minke B, Stephenson RS (1985) The characteristics of chemically induced noise in Musca photoreceptors. J Comp Physiol 156:339-356.

Nikolic K, Loizu J, Degenaar P, Toumazou C (2010) A stochastic model of the single photon response in Drosophila photoreceptors. Integr Biol (Camb) 2:354-370

Oberwinkler J, Stavenga DG (2000) Calcium imaging demonstrates colocalization of calcium influx and extrusion in fly photoreceptors. Proc Natl Acad Sci U S A 97:8578-8583.

Parnas M, Katz B, Minke B (2007) Open channel block by $\mathrm{Ca}^{2+}$ underlies the voltage dependence of Drosophila TRPL channel. J Gen Physiol 129:17-28.

Parnas M, Katz B, Lev S, Tzarfaty V, Dadon D, Gordon-Shaag A, Metzner H, Yaka R, Minke B (2009) Membrane lipid modulations remove divalent open channel block from TRP-like and NMDA channels. J Neurosci 29:2371-2383.

Pearn MT, Randall LL, Shortridge RD, Burg MG, Pak WL (1996) Molecular, biochemical, and electrophysiological characterization of Drosophila norpA mutants. J Biol Chem 271:4937-4945.

Peretz A, Suss-Toby E, Rom-Glas A, Arnon A, Payne R, Minke B (1994) The light response of Drosophila photoreceptors is accompanied by an increase in cellular calcium: effects of specific mutations. Neuron 12:1257-1267.

Pumir A, Graves J, Ranganathan R, Shraiman BI (2008) Systems analysis of the single photon response in invertebrate photoreceptors. Proc Natl Acad Sci U S A 105:10354-10359.

Rieger D, Fraunholz C, Popp J, Bichler D, Dittmann R, Helfrich-Förster C (2007) The fruit fly Drosophila melanogaster favors dim light and times its activity peaks to early dawn and late dusk. J Biol Rhythms 22:387-399.

Running Deer JL, Hurley JB, Yarfitz SL (1995) G protein control of Drosophila photoreceptor phospholipase C. J Biol Chem 270:12623-12628.

Schwertz DW, Halverson JB, Palmer JW, Feinberg H (1987) Characterization of phospholipase C-mediated phosphatidylinositol degradation in rat heart ventricle. Arch Biochem Biophys 253:388-398.

Scott K, Becker A, Sun Y, Hardy R, Zuker C (1995) Gqa protein function in vivo: genetic dissection of its role in photoreceptor cell physiology. Neuron 15:919-927.

Selinger Z, Minke B (1988) Inositol lipid cascade of vision studied in mutant flies. Cold Spring Harb Symp Quant Biol 53:333-341.

Siekhaus DE, Drubin DG (2003) Spontaneous receptor-independent heterotrimeric G-protein signalling in an RGS mutant. Nat Cell Biol 5:231-235.

Toyoshima S, Matsumoto N, Wang P, Inoue H, Yoshioka T, Hotta Y, Osawa T (1990) Purification and partial amino acid sequences of phosphoinositidespecific phospholipase C of Drosophila eye. J Biol Chem 265:14842-14848.

Wong F, Knight BW, Dodge FA (1980) Dispersion of latencies in photoreceptors of Limulus and the adapting-bump model. J Gen Physiol 76:517-537.

Wu CF, Pak WL (1975) Quantal basis of photoreceptor spectral sensitivity of Drosophila melanogaster. J Gen Physiol 66:149-168.

Yau KW, Hardie RC (2009) Phototransduction motifs and variations. Cell 139:246-264.

Yeandle S, Spiegler JB (1973) Light-evoked and spontaneous discrete waves in the ventral nerve photoreceptor of Limulus. J Gen Physiol 61:552-571.

Yoon J, Leung HT, Lee S, Geng C, Kim Y, Baek K, Pak WL (2004) Specific molecular alterations in the norpA-encoded phospholipase C of Drosophila and their effects on electrophysiological responses in vivo. J Neurochem 89:998-1008.

Yotsushima K, Mitsui T, Takaoka T, Hayakawa T, Igaue I (1993) Purification and characterization of membrane-bound inositol phospholipidspecific phospholipase C from suspension-cultured rice (Oryza sativa L.) cells (identification of a regulatory factor). Plant Physiol 102:165-172. 